\title{
Comprehensive Studies on Amino Acid Based Organometallic L-Threoninum Cobalt (li) Sulfate (Ltcs) Single Crystal
}

S V ASHVIN SANTHIA ( $\sim$ ashvinsanthia@gmail.com )

NESAMONY MEMORIAL CHRISTIAN COLLEGE https://orcid.org/0000-0001-8009-6564

B ANEEBA

NESAMONY MEMORIAL CHRISTIAN COLLEGE

$S$ VINU

Arts and Science College,NAGERCOIL

R SHEELA CHRISTY

NESAMONY MEMORIAL CHRISTIAN COLLEGE

\section{Research Article}

Keywords: Crystal growth, Optical constants, , NLO properties, Mechanical behavior, Antimicrobial assay

Posted Date: March 6th, 2021

DOI: https://doi.org/10.21203/rs.3.rs-279768/v1

License: @ (i) This work is licensed under a Creative Commons Attribution 4.0 International License.

Read Full License 


\title{
COMPREHENSIVE STUDIES ON AMINO ACID BASED ORGANOMETALLIC L-THREONINUM COBALT (II) SULFATE (LTCS) SINGLE CRYSTAL
}

\author{
S.V.ASHVIN SANTHIA ${ }^{1 *}$, B.ANEEBA ${ }^{2}$, S.VINU $^{3}$, R.SHEELA CHRISTY ${ }^{4}$ \\ 1* Department of Physics and Research Centre, Nesamony Memorial Christian College, Marthandam, \\ Reg.No: 18123112132036, Affiliated to Manonmaniam Sundaranar University, Abishekapatti, Tirunelveli, \\ Tamil Nadu, India. \\ ${ }^{2,4}$ Department of Physics and Research Centre, Nesamony Memorial Christian College, Marthandam, Tamil \\ Nadu, India. \\ ${ }^{3}$ Department of Physics, Govt. Arts and Science College, Nagercoil, Tamil Nadu, India. \\ *Corresponding authors: vinusnist@gmail.com, ashvinsanthia@gmail.com
}

\begin{abstract}
By the most widely used slow evaporation technique at room temperature, L-Threoninum Cobalt (II) Sulfate Heptahydrate (LTCS) materials were grown for various applications. The structure of orthorhombic LTCS was identified by X-Ray Diffraction studies (Powder X-Ray Diffraction and Single crystal X-Ray Diffraction), this analysis has also reported the crystallinity, cell parameters $(a=5.35, b=7.93, c=13.71)$, and space group (non-centrosymmetric) of the grown material. Functional groups were affirmed by FTIR analysis. Optical analysis straightforwardly confirms LTCS crystals has greater optical transparency, and $E g=5.6 \mathrm{eV}$ demonstrates the appropriateness of prepared crystals to optical applications. The mechanical properties were validated with the aid of Vickers' microhardness measurement and that also suggests LTCS belongs to the class of hard material. In this respect, the SHG efficiency of the LTCS crystal grown is 1.25 times greater than that of the KDP crystal because $\mathrm{Co}^{+}$ions boost the SHG efficiency of LTCS and it was tested by Kurtz and Perry's technique. Electrical results documented the good conducting properties of LTCS crystal. The LTCS substance used to treat fungal and bacterial infections and this bacterial and fungal destroying property was validated by an antimicrobial assay.
\end{abstract}

\section{Keywords}

Crystal growth, Optical constants, , NLO properties, Mechanical behavior, Antimicrobial assay. 


\section{INTRODUCTION}

In the newest scenario, crystal growth plays an interdisciplinary activity in numerous areas of physics, chemistry, and molecular biology due to its notable benefits. In the age of informatics; in multidisciplinary nature of technology (information) is handled at high speed by integrated circuits built on a single crystal. On the other hand, in microelectronics, communication technology, energy and space technology single crystal with high quality is required, because single crystals are capable of changing their properties under the influence of light, electric and magnetic field, temperature and pressure, etc. Among various organic and inorganic materials, semi-organic materials cater to an innumerable scope in various practical applications. At present amino acids combined with a variety of inorganic materials single crystals can be formed and they have received broad attention for the above-mentioned applications, because in the zwitterionic state amino acid may produce an added betterment in various practical applications [1,2]. Unlike other amino acids, L-threonine is capable of forming compounds with organic and inorganic compounds, and also it is an essential amino acid often used to support the production of connective tissue [3, 4]. Inorganic Cobalt (II) Sulfate has lot of applications such as preparation of pigments and manufacture of other cobalt salts etc., and also it may play a vital role in various biological activities $[5,6]$.

\section{MATERIALS AND METHODS}

\subsection{Materials and crystal growth}

A comfortable slow evaporation solution growth mechanism was used at a constant temperature for the production of high quality LTCS material. The equimolar ratio of L-Threonine and Cobalt (II) Sulfate heptahydrate was chosen to take for the production of LTCS substance and it is dissolved in the solvent

(distilled water). For the removal of contaminants, the very well mixture solution was filtered and wrapped in perforated foil, and preserved in uninterrupted condition for evaporation. The high transparency LTCS single crystal was gathered after 25-30 days without defects, and is being shown in Fig.1. 




Fig. 1 Photograph of LTCS single crystal

\subsection{Characterization techniques}

Only for the determination of unit cell parameters of the titular crystals, the Bruker Kappa APEXII $\mathrm{X}$-ray diffractometer was used. By using the XPERT-PRO diffractometer with $\mathrm{Cu}$ k $\alpha$ radiation $(\lambda=1.5406$ $\AA$ ), the crystallinity of the LTCS crystal was checked. Functional groups of the LTCS crystals are trialed by Thermo Nicolet Avatar 370 spectrometers in the frequency region 400-4000 cm-1. By UV-1700 Series Spectrophotometer optical character of LTCS crystal was measured in the range of 200-800 nm. The mechanical behavior of LTCS was investigated by an HMV-2T microhardness tester. The mechanical behavior of grown crystals was validated by an HMV-2T microhardness tester. By the Tonghui TH2826 Precision LCR Meter, the dielectric behavior was observed. To assess the presence of antibacterial activity of LTCS was carried out by the Agar disk diffusion method with aminoglycoside antibiotics Amikacin as a control for antibacterial activity and Nystatin was used as a control for fungicide activity studies of the grown material.

\section{RESULTS AND DISCUSSION}

\subsection{Single crystal X-ray diffraction analysis (SXRD)}

The data obtained from SXRD measurement are unit cell parameters, crystal system, and space group. A system with orthorhombic structured LTCS was identified along with this analysis and also SXRD confirms the LTCS crystal belongs to non-centrosymmetric space group $\mathrm{P} 2{ }_{1} 2_{1} 2_{1}$. The unit cell parameters of grown sample collected from SXRD measurement are presented in Table 1. 
Table 1 Structural parameters of LTCS crystal

\begin{tabular}{|c|c|}
\hline Crystal property & Parameter \\
\hline Crystal System & Orthorhombic \\
\hline Space group & $\mathrm{P} 2{ }_{1} 2_{1} 2_{1}$ \\
\hline Unit cell parameter & $\mathrm{c}=5.35, \mathrm{~b}=7.93$, \\
\hline Volume of the unit cell & $581 \AA^{3}$ \\
\hline Radiation wavelength & $\lambda=0.71073 \AA$ \\
\hline
\end{tabular}

\subsection{Powder X-ray diffraction analysis (PXRD)}

The grown LTCS crystal has been subjected to PXRD measurement because it provides information about the symmetry of unit cell, atom position, and displacements of crystalline material via the position and intensities of the diffraction reflection [7, 8]. The crystalline nature of LTCS and material's purity were confirmed by an accurate description of line profile shapes as shown in Fig. 2.

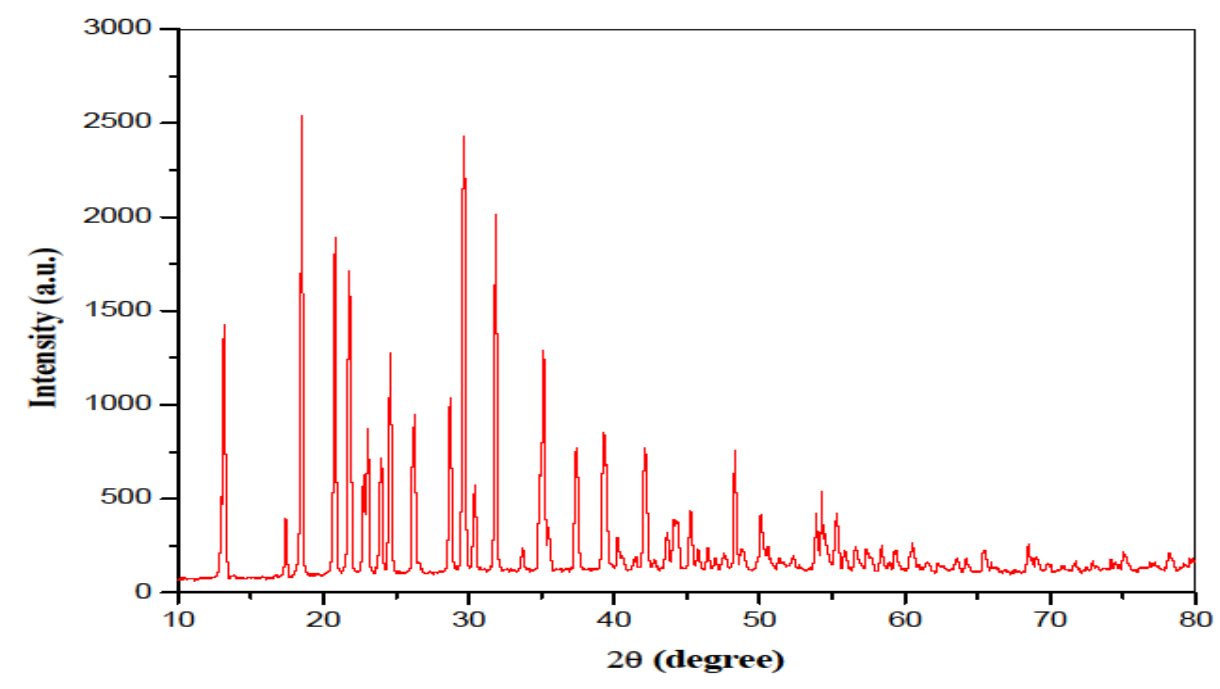

Fig. 2 Powder XRD pattern of LTCS crystal 


\subsection{FTIR analysis}

FTIR is a non-destructive powerful analytical technique for producing a unique fingerprint of the sample. Herein the bonding structure and the diverse functional groups for the synthesized crystal were analyzed by FTIR technique. The resulting FTIR spectrum of LTCS has been illustrated in Fig.3 and it shows that LTCS molecules exist in the zwitter ionic state due to the presence of amine group, carboxylate group, and hydrogen bonding [9]. The observed wavenumbers and the proposed assignments of the LTCS crystal's FTIR spectrum band are given in Table 2.

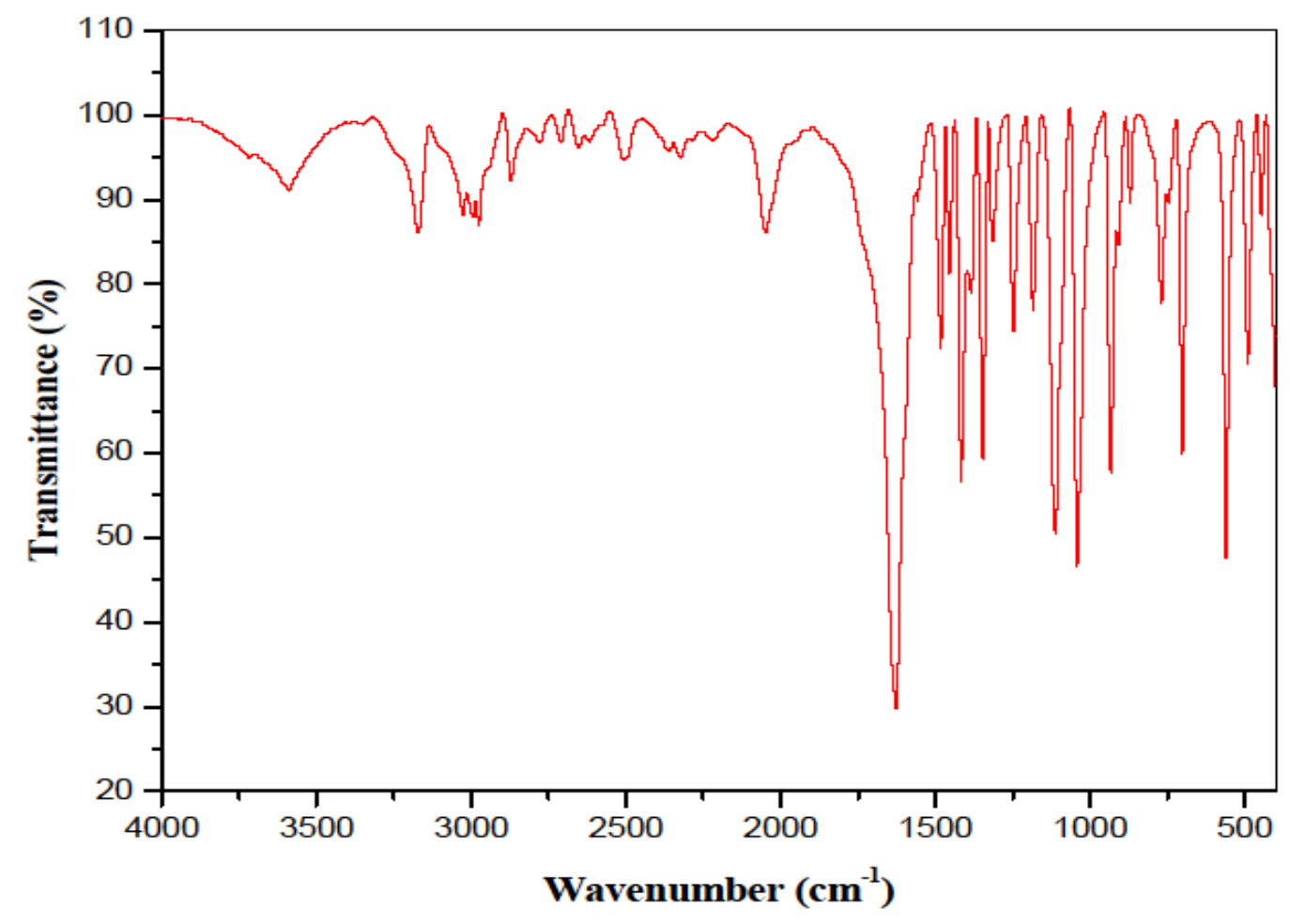

Fig.3 FTIR spectra of LTCS crystal 
Table 2 FTIR assignments of the LTCS crystal

\begin{tabular}{|c|c|}
\hline Wave number & Functional group \\
\hline 3585.74 & O-H Symmetric stretching \\
\hline 3170.76 & $\mathrm{NH}^{3+}$ asymmetric stretching \\
\hline 3032.43 & $\mathrm{NH}_{3}{ }^{+}$stretching \\
\hline 2980.45 & $\mathrm{CH}_{3}$ symmetric stretching \\
\hline 2858.90 & O-H stretching \\
\hline 2054.46 & $\mathrm{CH}_{3}$ stretching \\
\hline 1621.85 & $\mathrm{NH}_{3}{ }^{+}$asymmetric bending \\
\hline 1474.72 & $\mathrm{NH}_{3}{ }^{+}$symmetric bending \\
\hline 1405.95 & $\mathrm{CO} 2$ - symmetric stretching \\
\hline 1353.97 & $\mathrm{CH}_{3}$ bending \\
\hline 1293.20 & $\mathrm{CH}_{3}$ bending \\
\hline 1250.02 & $\mathrm{CH}_{3}$ bending \\
\hline 1180.45 and 1111.68 & $\mathrm{NH}_{3}$ rocking \\
\hline 1042.11 & C-N stretching \\
\hline 930.16 & C-C stretching \\
\hline 860.59 & $\mathrm{CO}_{2}^{-}$bending \\
\hline 774.23 & $\mathrm{COH}$ torsion \\
\hline 696.66 & $\mathrm{CO}_{2}^{-}$Wagging vibration \\
\hline 557.52 & C-C-N group deformation vibration \\
\hline 479.96 & $\mathrm{NH}_{3}$ torsional mode \\
\hline
\end{tabular}




\subsection{UV-Visible spectral analysis}

The improvements that light travels throughout the substance by altering its vector of propagation or strength with a specific material are described as the optical characteristics of that substance [10]. Including a very well, the most important optical properties: absorption, propagation, reflection, and refraction. Some optical constants such as refractive index (n) and extinction coefficient (K) are correlated with these properties and can be calculated by calculating the reflectance of a material. The transmittance spectrum of the LTCS crystal in Fig. 4.1 shows a wide transparency window from 235 to $800 \mathrm{~nm}$ and no absorbance in the entire wavelength indicating that the LTCS crystal possess greater optical transparency and the prepared crystals were suitable for NLO applications [11-13]. In this present work the value of $E_{g}=5.6 \mathrm{eV}$ obtained from

Fig. 4.2. The optical absorption coefficient $(\alpha)$ and $E_{g}$ according to Tauc's relationship is given by [14]

$\alpha=\frac{2.303}{t} \log \frac{1}{T}$

where $\mathrm{T}$ is the transmittance and $\mathrm{t}$ is thickness of crystal.

$\alpha h v=A\left(h v-E_{g}\right)^{n}$

2

where $\mathrm{A}$ is a constant, $E_{g}$ the optical band gap, $h$ the plank's constant and $v$ the frequency of incident photons and value of $\mathrm{n}$ is depend upon the nature of transition.

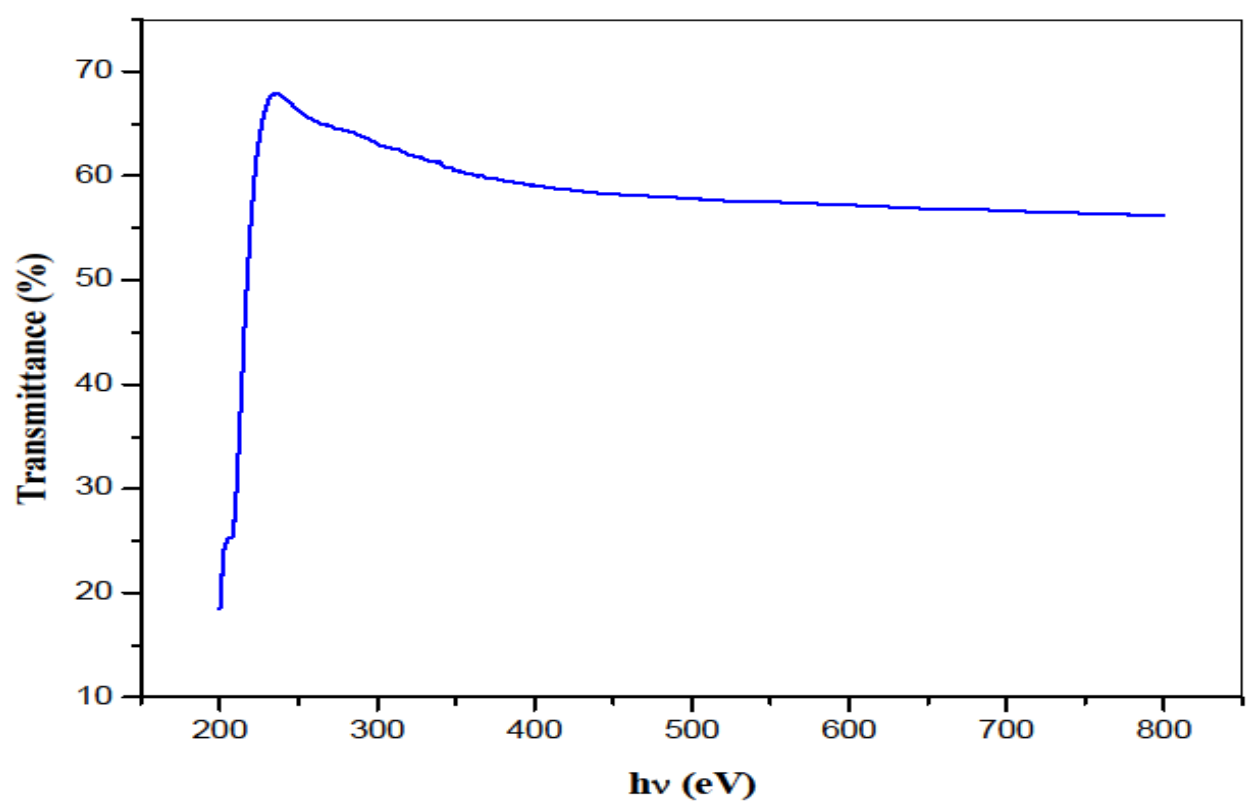




\section{Fig. 4.1 Transmission spectra of LTCS crystal}

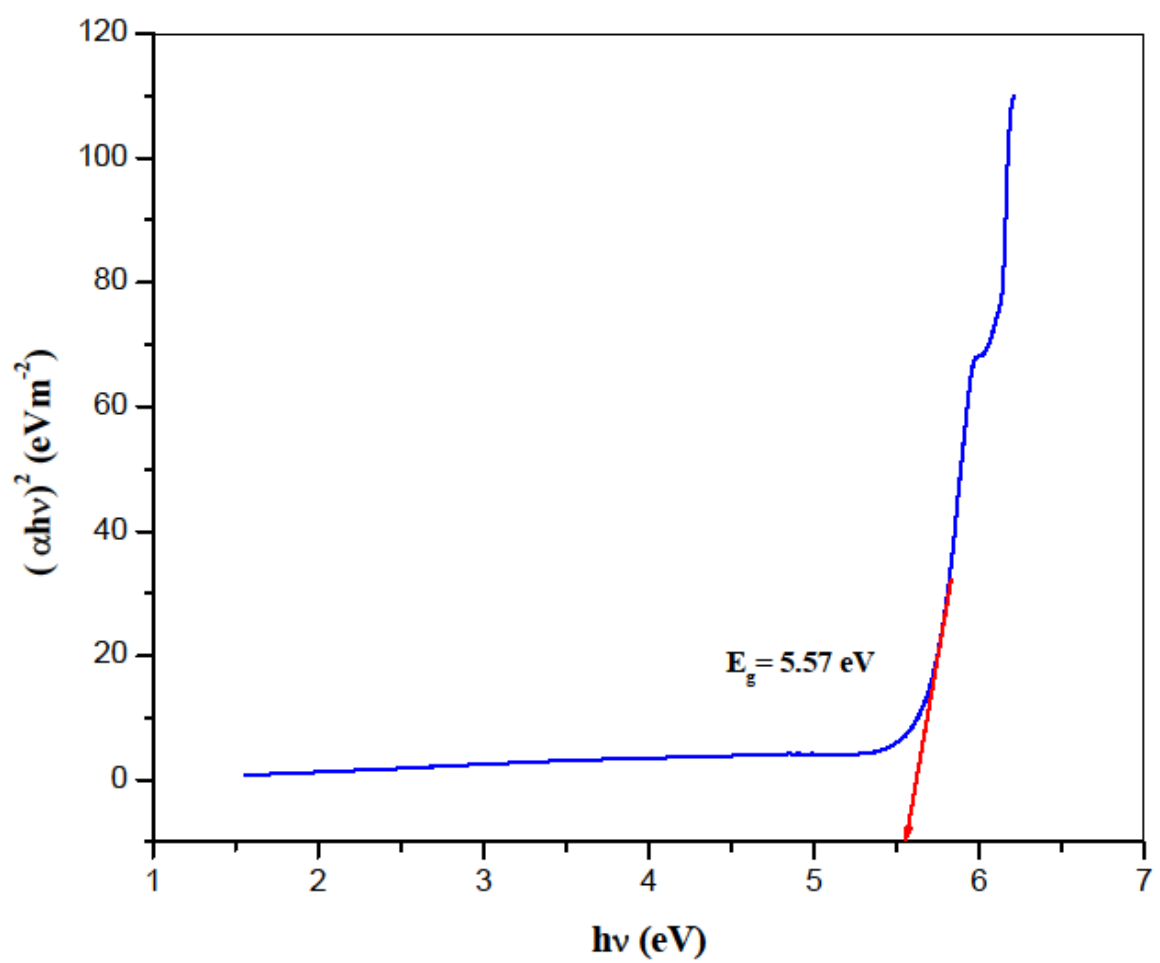

Fig. 4.2 Plot of $(\alpha h v)^{2}$ versus Photon energy (hv) of LTCS crystal

The absorption loss $(\mathrm{K})$ due to propagation of the electromagnetic wave is shown in Fig. 4.3 and it shows $\mathrm{K}$ is not constant, but still depends strongly on the frequency of light. The obtained $\mathrm{n}$ of the grown crystal plotted against photon energy as shown in Fig. 4.4.It is observed from the figure that, $\mathrm{n}$ values are between 0.9 and 1.6. This confirms the high transmittance nature of the grown material $[15,16]$. The following formulas are used for calculating $\mathrm{K}$ and refractive index.

$K=\frac{\lambda \alpha}{4 \pi}$

$n=-\frac{(R+1) \pm \sqrt{3 R^{2}+10 R-3}}{2(R-1)}$ 


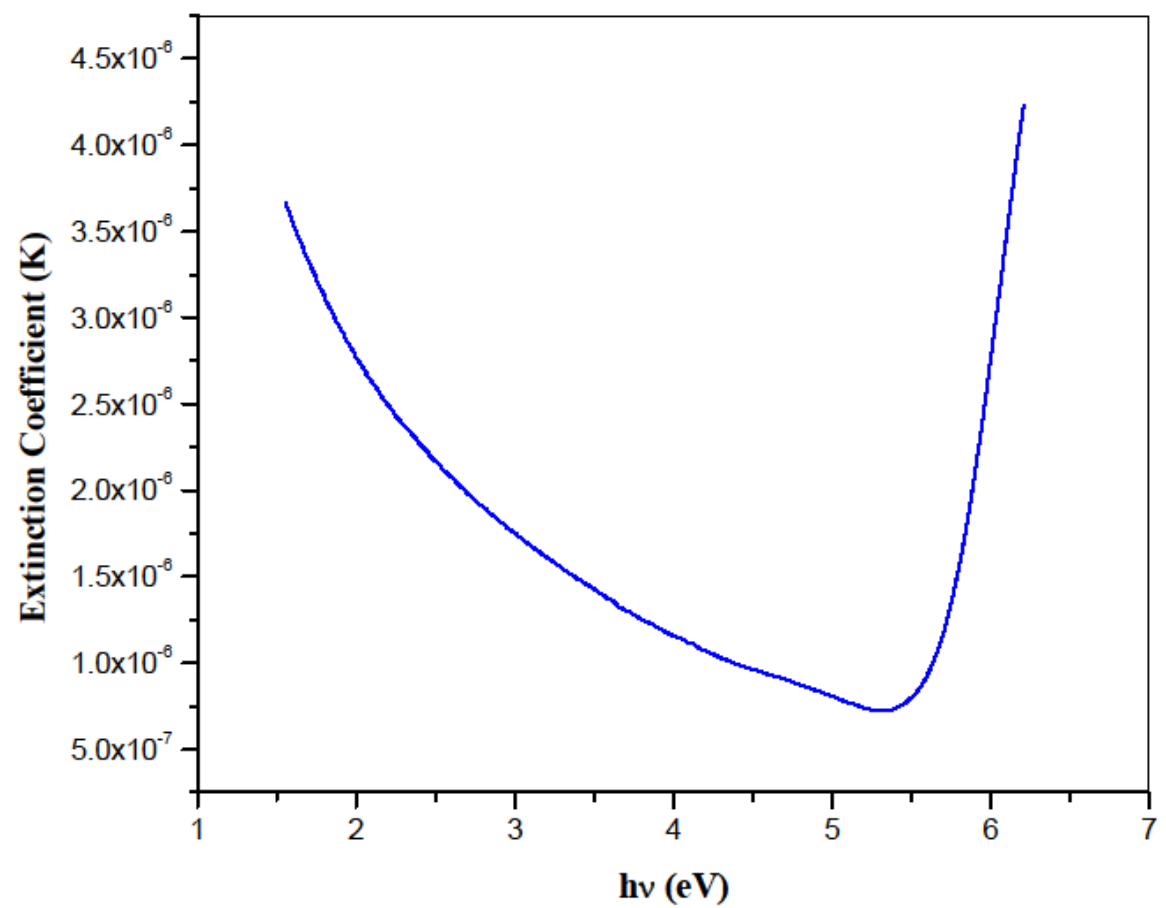

Fig. 4.3 Photon energy versus Extinction Coefficient of LTCS crystal

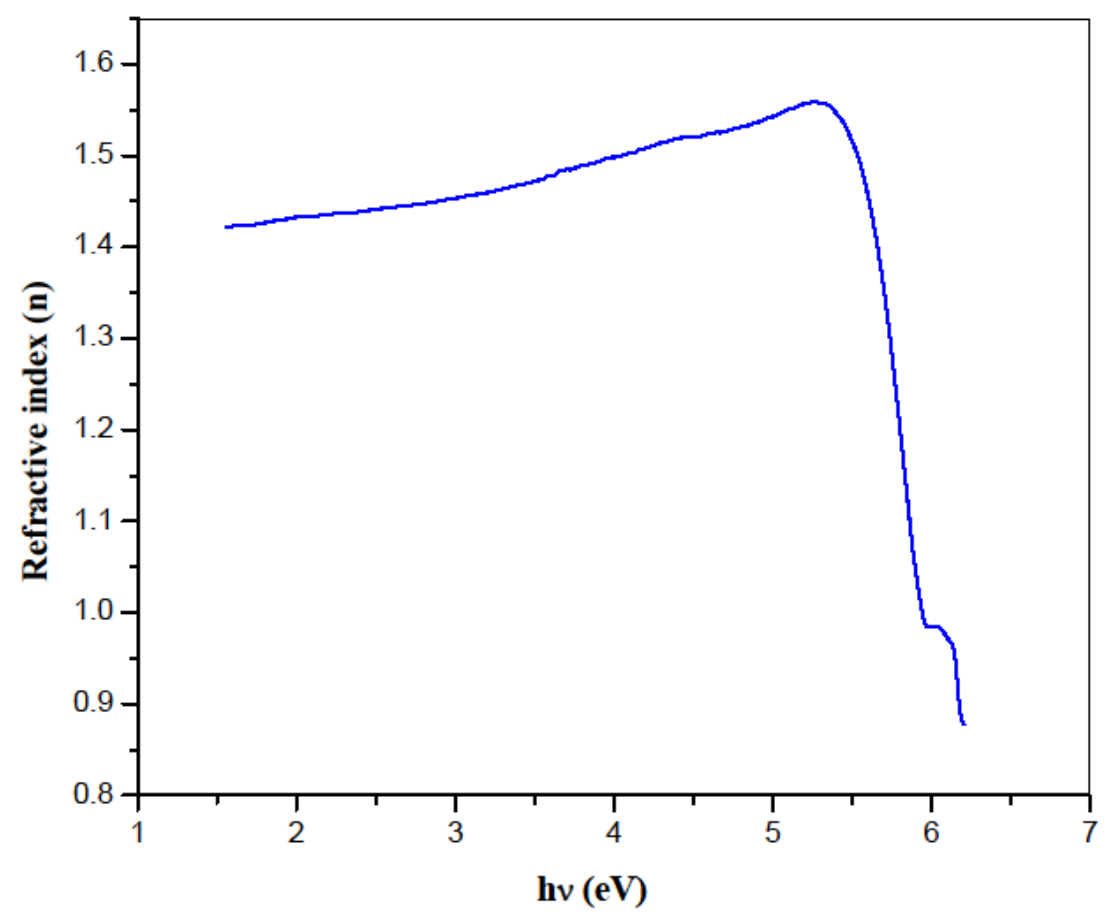

Fig. 4.4 Photon energy versus refractive indices of LTCS crystal 
The other optical properties such as $\delta$ and $\sigma$ versus photon energy are shown in Fig. 4.5 and Fig. 4.6. The skin depth is a way of measuring the penetration of an electromagnetic wave into an object. It can be numerically define as.

$\delta=\frac{1}{\alpha}$

Optical conductivity is given by the relation

$\sigma=\frac{\alpha n c}{4 \pi}$

Where $\mathrm{c}$ is the speed of light (free space), $\mathrm{n}$ is refractive index, $\alpha$ is the absorption coefficient. This $\delta$ and $\sigma$ strongly dependent on photon energy of the grown material indicating the phototunable nature of the titular material.

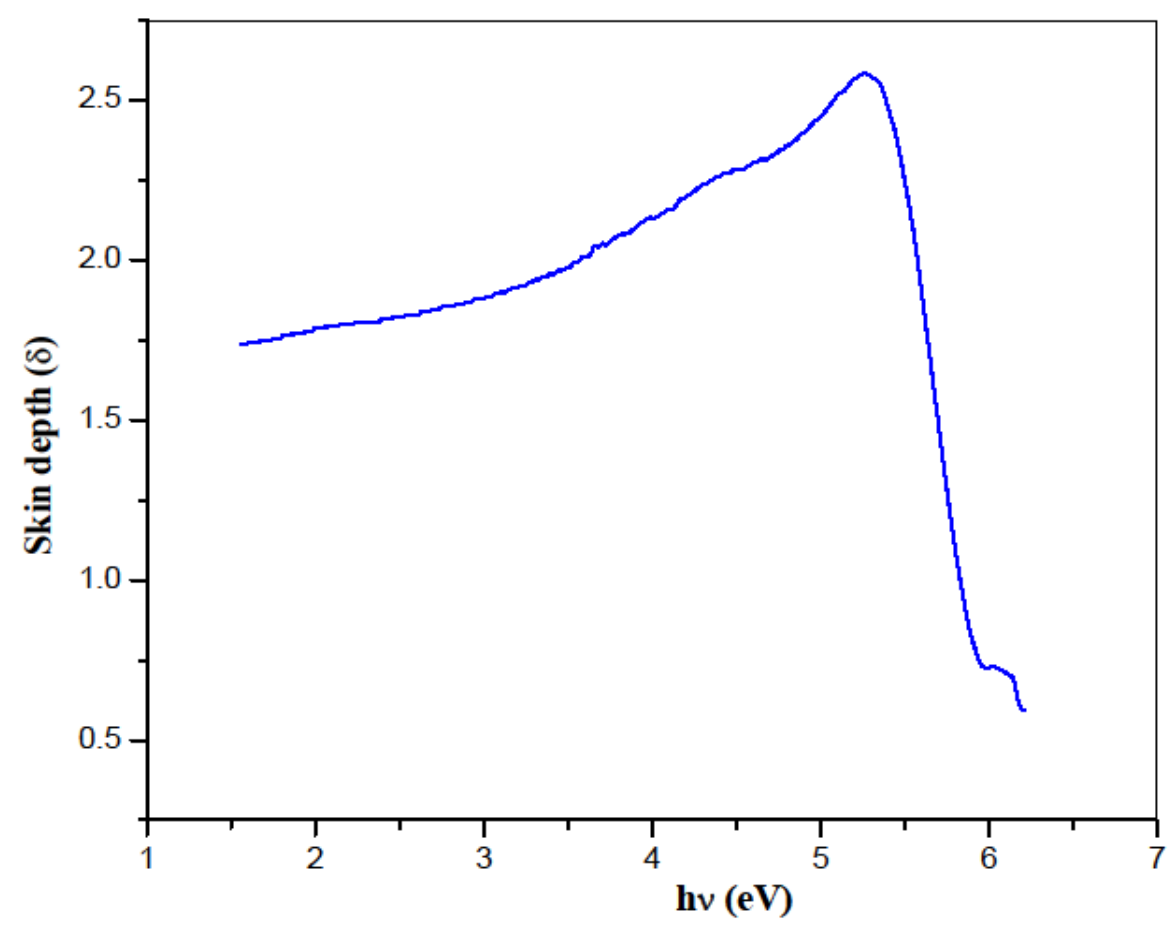

Fig. 4.5 Photon energy versus Skin depth of LTCS crystal 


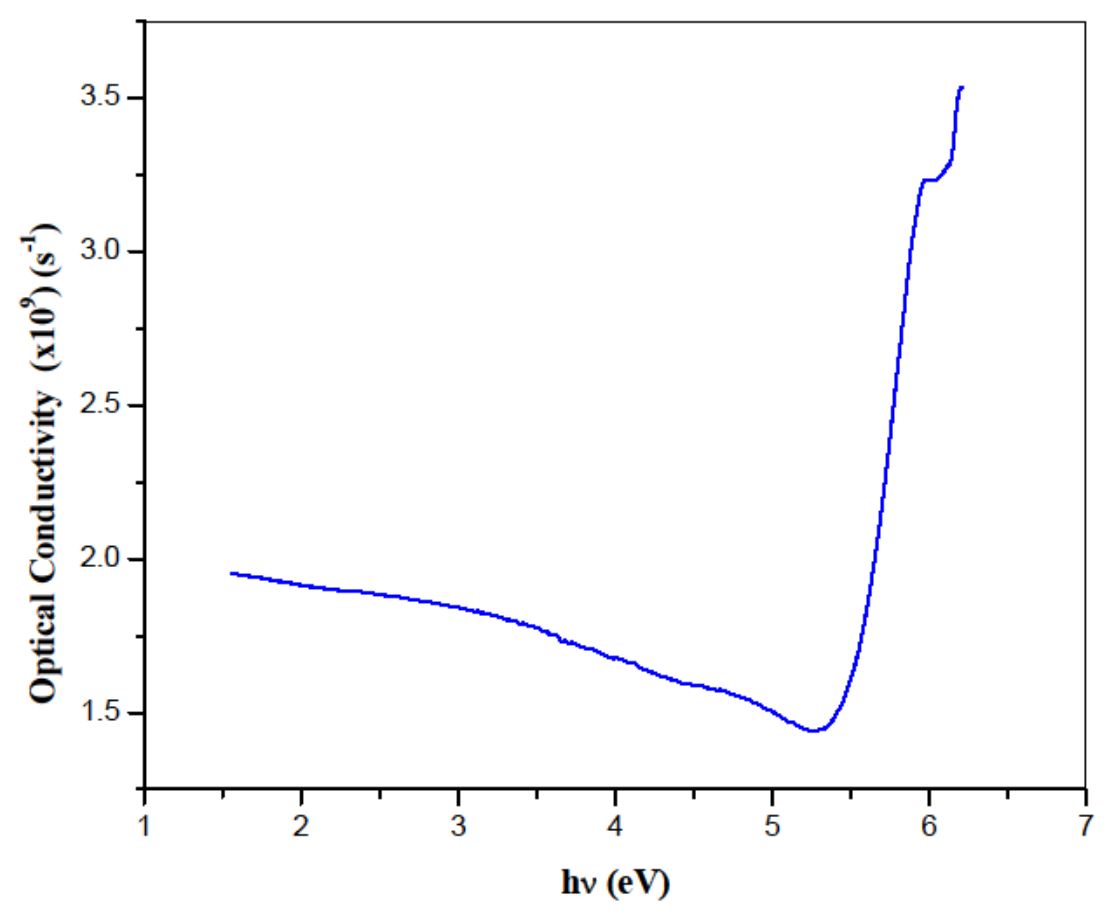

Fig. 4.6 Photon energy versus optical conductivity of LTCS crystal

\subsection{Hardness measurement}

Hardness is a simple parameter to measure the resistance of the material to permanent deformation. For most materials hardness measurements can be made at low loads $<200$ gram is called microhardness. This low load hardness is a major parameter to evaluate the mechanical property such as Hardness $\left(\mathrm{H}_{\mathrm{v}}\right)$, Fracture toughness $\left(\mathrm{K}_{\mathrm{c}}\right)$, Brittleness index $\left(\mathrm{B}_{\mathrm{i}}\right)$, Yield strength $\left(\sigma_{\mathrm{v}}\right)$, Stiffness constant $\left(\mathrm{C}_{11}\right)$ of the material by varying the load below 200 gram [17,18]. With the help of this simple and popular non-destructive measurement the mechanical characterizations of the LTCS material was studied. The indentations on the LTCS crystal were carried out under different loads between $25 \mathrm{~g}$ and $100 \mathrm{~g}$. When the loaded indenter is pressed on the surface of the material it creates dislocations and the movement of dislocation is obstructed by impurities, other dislocations, grain boundaries, some intrinsic properties of the materials, and the like. Thus, if the material high quality, defect free, the hardness is high. The mechanical parameters of the titular material are presented in Table 6.3.

For LTCS material $\mathrm{H}_{\mathrm{v}}$ increase with rising load indicates RISE (reverse indentation size effect RISE) which is presented in Fig.5.1. The work hardening coefficient (n) value of LTCS crystal is 3.7, which is obtained from Fig.5.2, and it confirms that LTCS is a soft material category. The Vickers hardness number is thus calculated using the relation [19] 
$\mathrm{H}_{v}=1.8544 \mathrm{P} / \mathrm{d}^{2}$

Where $\mathrm{P}$ is the applied load in $\mathrm{kg}$ and $\mathrm{d}$ is the diagonal length of the indentation mark in $\mathrm{mm}$.

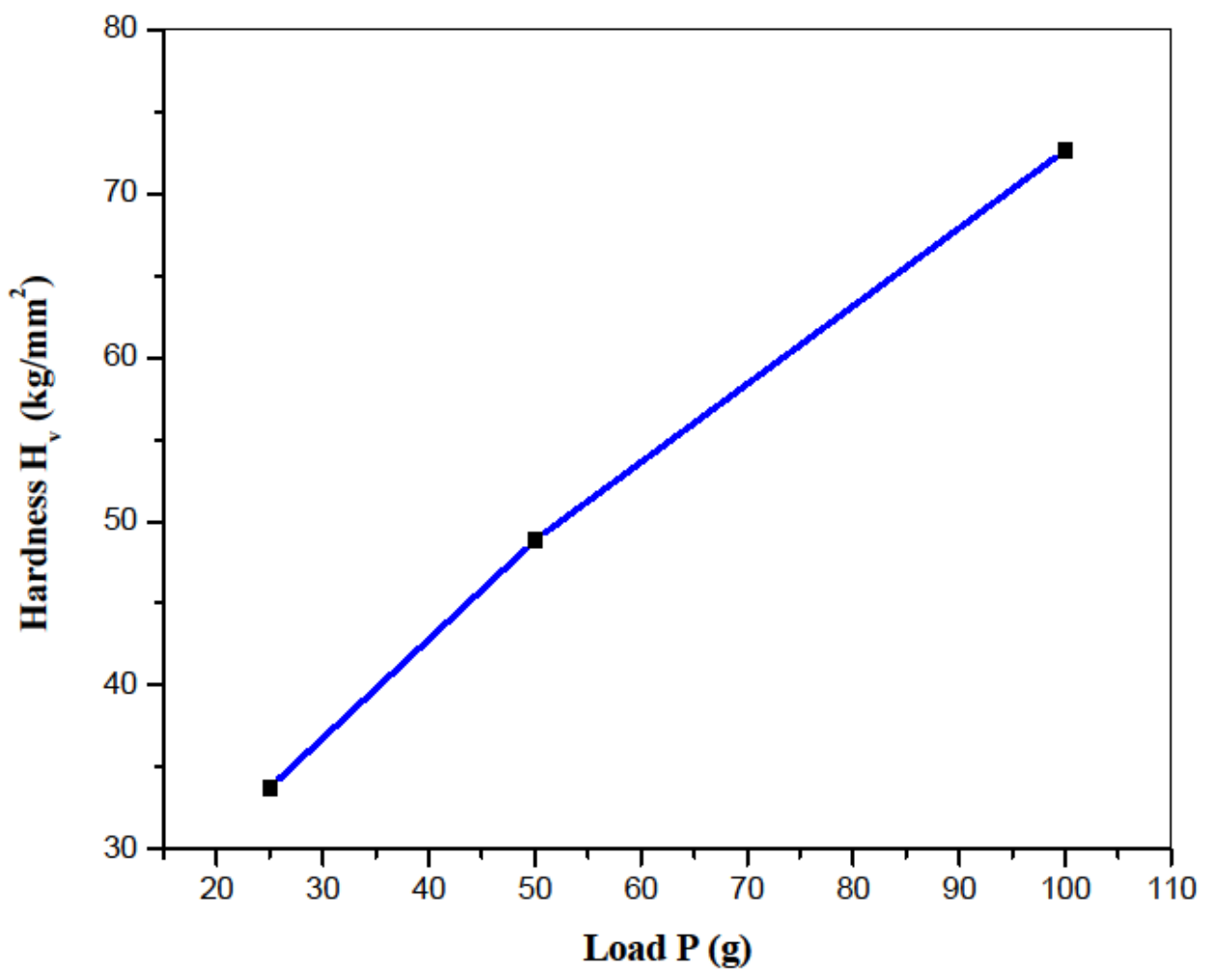

Fig. 5.1 Hardness versus load P of LTCS crystal

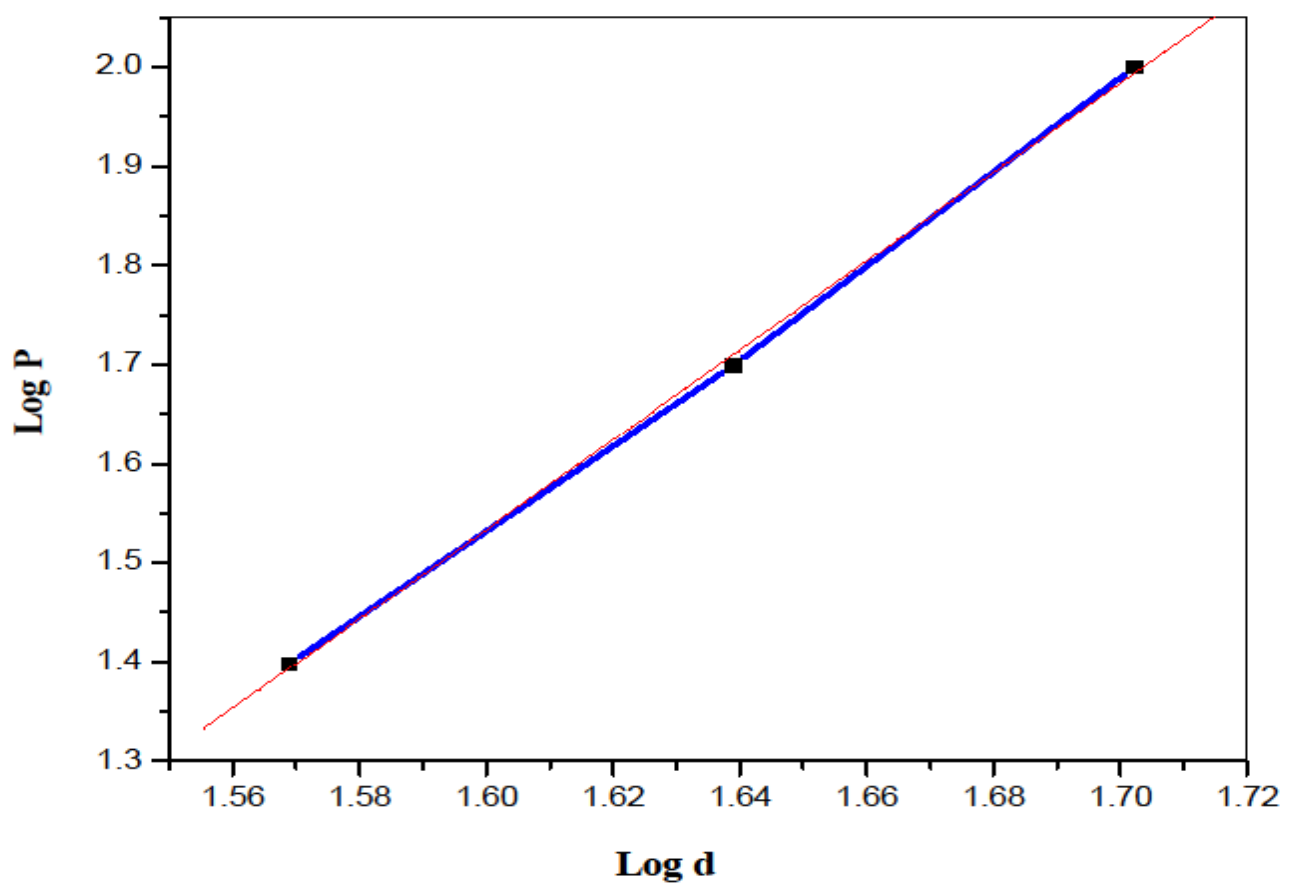

Fig. 5.2 Log P versus Log d of LTCS crystal 
Fracture toughness is the property of materials able to resist the fracture and the following relation is used to calculate $\mathrm{K}_{\mathrm{c}}$ (Fracture toughness),

$$
K_{c}=\frac{P}{\beta C^{3 / 2}}
$$

Increase in $\mathrm{K}_{\mathrm{c}}$ with applied load indicates high mechanical stability of the LTCS material (Fig.5.3).

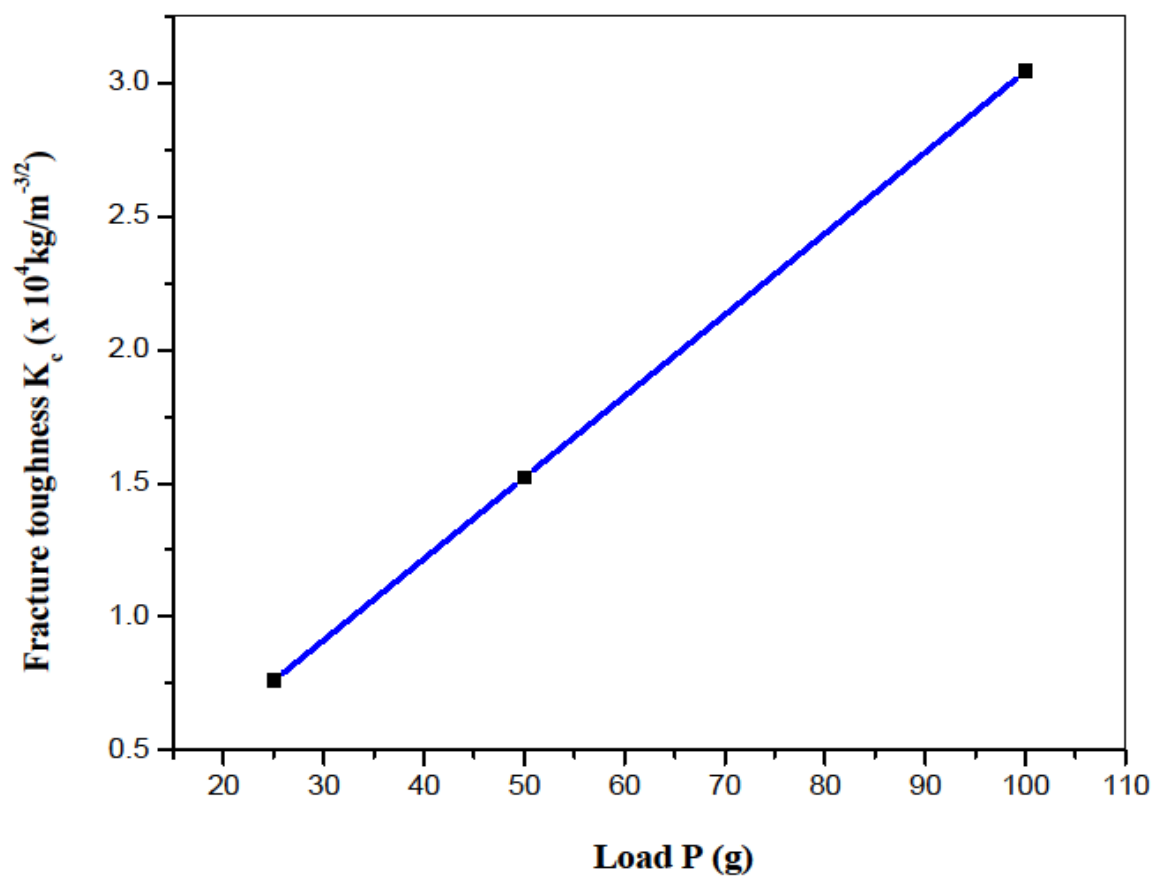

Fig. 5.3 Fracture toughness versus load P of LTCS crystal

Fig.5.4 shows decrease in brittleness index $\left(B_{i}\right)$ with increase in load indicates LTCS material is suitable for device fabrication. Brittleness index $\left(\mathrm{B}_{\mathrm{i}}\right)$ can be calculated by the following relation,

$B_{i}=\frac{H_{v}}{K_{c}}$ 


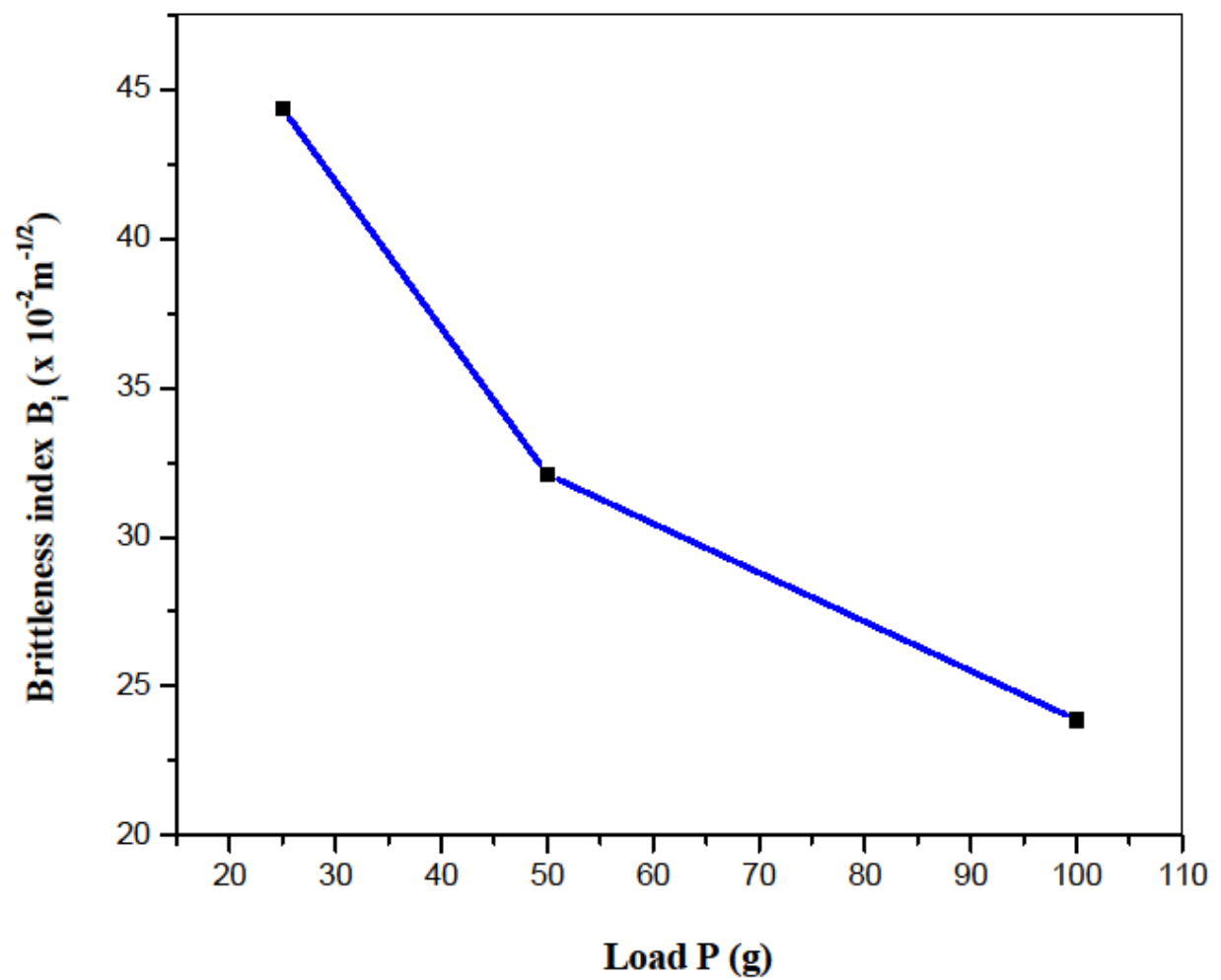

Fig.5.4 Brittleness index versus load P of LTCS crystal

In device manufacturing and construction technology, yield strength seems to be a very significant mechanical property and it is calculated by using the relation [20,21].

$$
\begin{array}{ll}
\sigma_{v}=\frac{H_{v}}{2.9}\left\{[1-(n-2)]\left[\frac{12.5(n-2)}{(1-(n-2))}\right]^{n-2}\right\} & \text { for } \mathrm{n}>2 \\
\sigma_{v}=\frac{H_{v}}{3} & \text { for } \mathrm{n}<2
\end{array}
$$

where $\mathrm{n}$ is the microhardness index.

The increase in yield strength (Fig. 5.5) indicates the selection of materials for the field of engineering. 


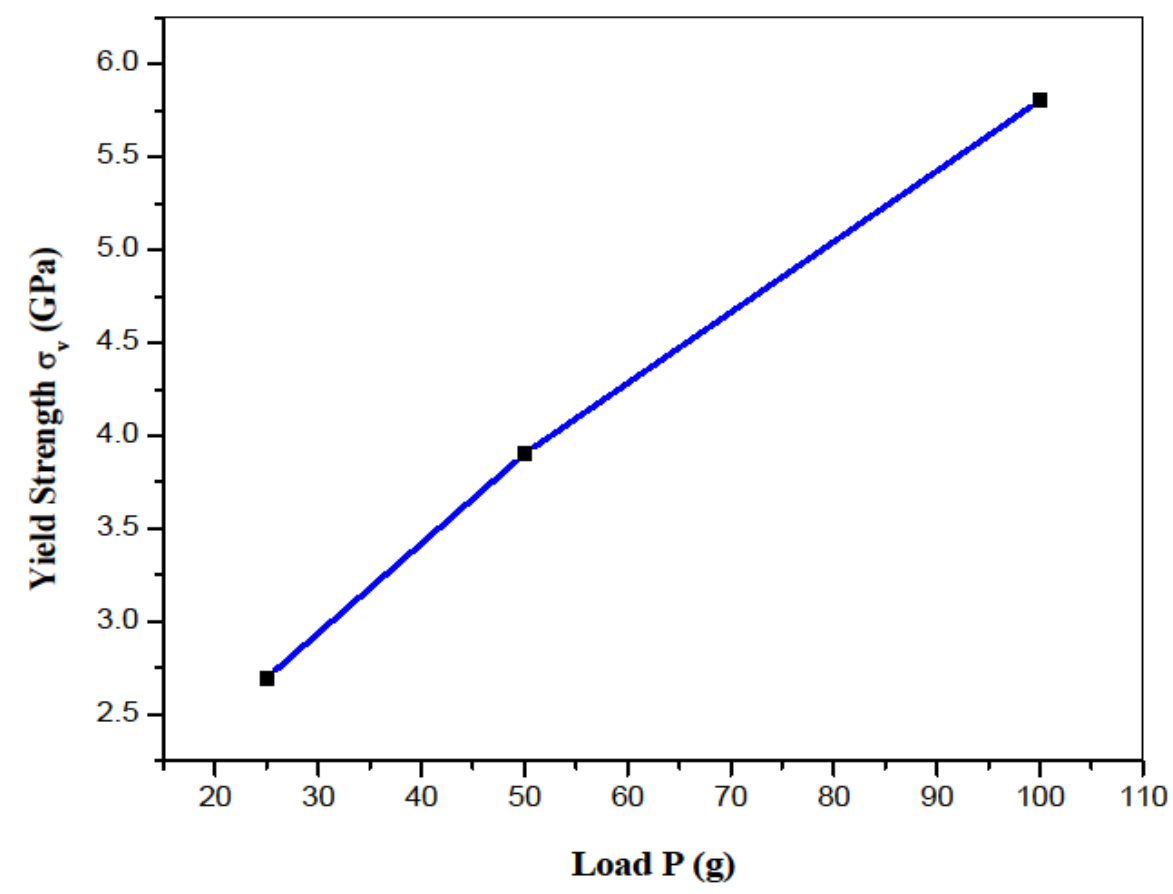

Fig. 5.5 Yield Strength versus load P of LTCS crystal

The stiffness constant $C_{11}$ can determine using Wooster's empirical formula,

$C_{11}=\left(H_{v}\right)^{7 / 4}$

Due to the high bonding nature of grown material, stiffness constant $\left(\mathrm{C}_{11}\right)$ increased by increasing load (Fig.5.6).

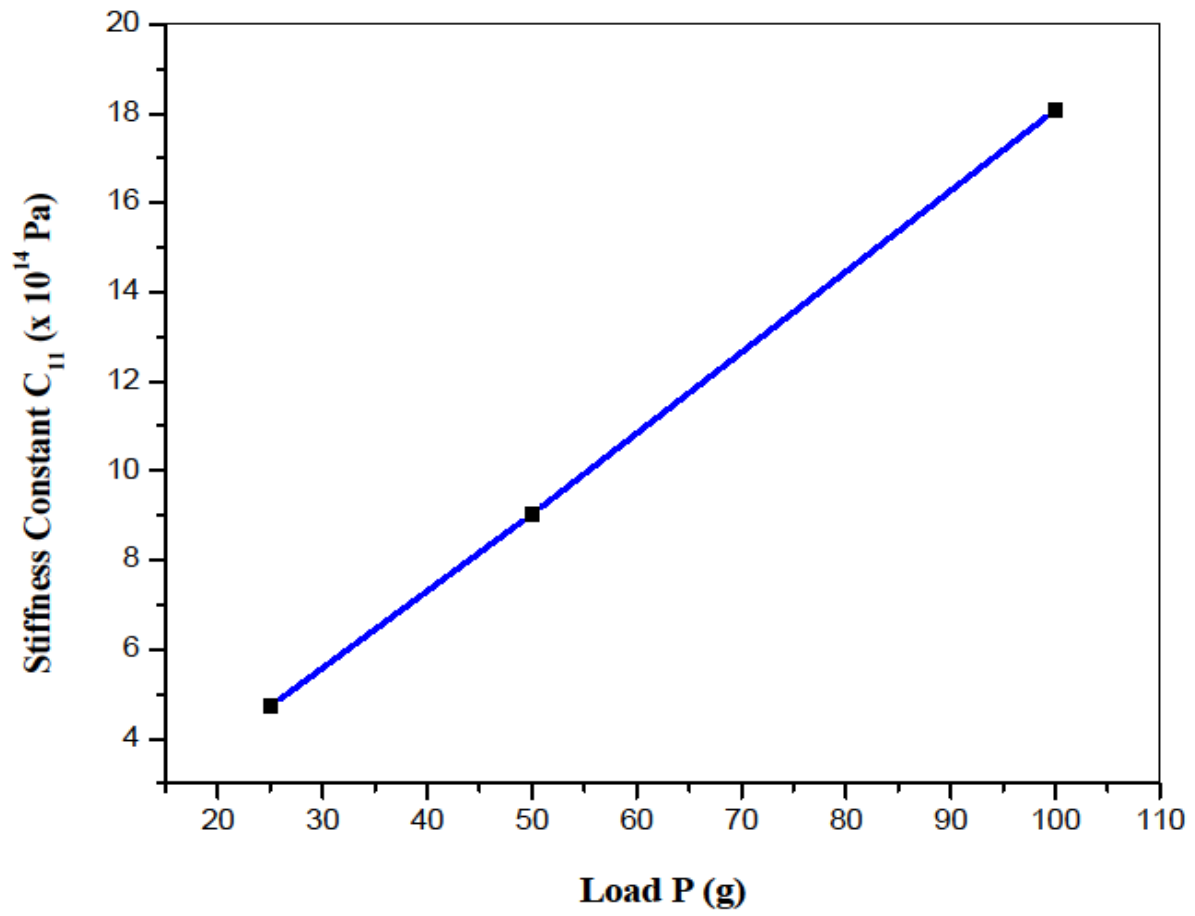


Fig. 5.6 Stiffness constant versus load P of LTCS crystal

Table 4 Mechanical parameters of LTCS crystal

\begin{tabular}{|l|c|c|c|c|c|}
\hline Load P $(\mathrm{g})$ & $\left(\mathrm{H}_{\mathrm{V}}\right)\left(\mathrm{kg} / \mathrm{mm}^{2}\right)$ & $\left(\mathrm{K}_{\mathrm{C}}\right)$ & $\left(\mathrm{B}_{\mathrm{i}}\right)$ & $\left(\sigma_{\mathrm{v}}\right)(\mathrm{GPa})$ & $\left(\mathrm{C}_{11}\right)$ \\
& & $\left(\times 10^{4} \mathrm{~kg} / \mathrm{m}^{-3 / 2}\right)$ & $\left(\times 10^{-2} \mathrm{~m}^{-1 / 2}\right)$ & & $\left(\times 10^{-14} \mathrm{~Pa}\right)$ \\
\hline 25 & 33.75 & 0.760 & 44.360 & 0.413 & 4.725 \\
\hline 50 & 48.85 & 1.521 & 32.103 & 0.599 & 9.026 \\
\hline 100 & & & & & \\
\hline
\end{tabular}

\subsection{SHG measurement}

The titular material was illuminated by the Q-switched Nd: YAG laser of $\lambda=1064 \mathrm{~nm}$ and the output energy (green light of $\lambda=532 \mathrm{~nm}$ ) were analyzed for the nonlinear SHG efficiency of the LTCS. Thus, obtained results were compared with standard reference KDP [22-24]. It is evident from the observation that $\mathrm{Co}^{+}$ion raises the SHG performance of grown LTCS crystal because the results obtained were 1.25 times higher than that of standard KDP crystal and it confirms LTCS can be used for numerous NLO applications $[25,26]$.

\subsection{Dielectric studies}

The dielectric analysis is indispensable for characterizing the electrical properties of the crystal and it also provides information related to the nature of defects in the crystal [27,28]. The frequency dependent plot of $\varepsilon_{r}$ 
in Fig.7.1 explains dielectric constant high at lower frequency side because the presence of all type of polarization and it gradually decreased at high frequency is due to the reduction of space charge polarization

The relative permittivity or the dielectric constant $\varepsilon_{r}$ is calculated by the following relation

$\varepsilon_{r}=\frac{C d}{\varepsilon_{0} A}$

Where all the symbols have their own significance

The dielectric loss depends very much on temperature and frequency and measured by the following relation,

$\tan \delta=\frac{1}{\omega R C}$

The $\tan \delta$ is referred to as the dielectric loss.

Fig.7.2 represents the frequency dependence of the dielectric loss tangent at various temperatures and it demonstrates also that loss tangent has a similar trend with dielectric constant. The high value of $\tan \delta$ at a low frequency can attribute to the high resistivity of the grain boundaries [29]. Fig.7.3 shows the variation of AC conductivity of LTCS material for $120^{\circ} \mathrm{C}$ within the $100 \mathrm{~Hz}$ to $2 \mathrm{MHz}$ frequency range. It was observed that with an increase in frequency, the $\mathrm{AC}$ conductivity was slowly rising up to $100 \mathrm{kHz}$ and a rapid linear increase thereafter. This study unambiguously identifies the grown crystal is less defective, good quality material $[30,31]$. 


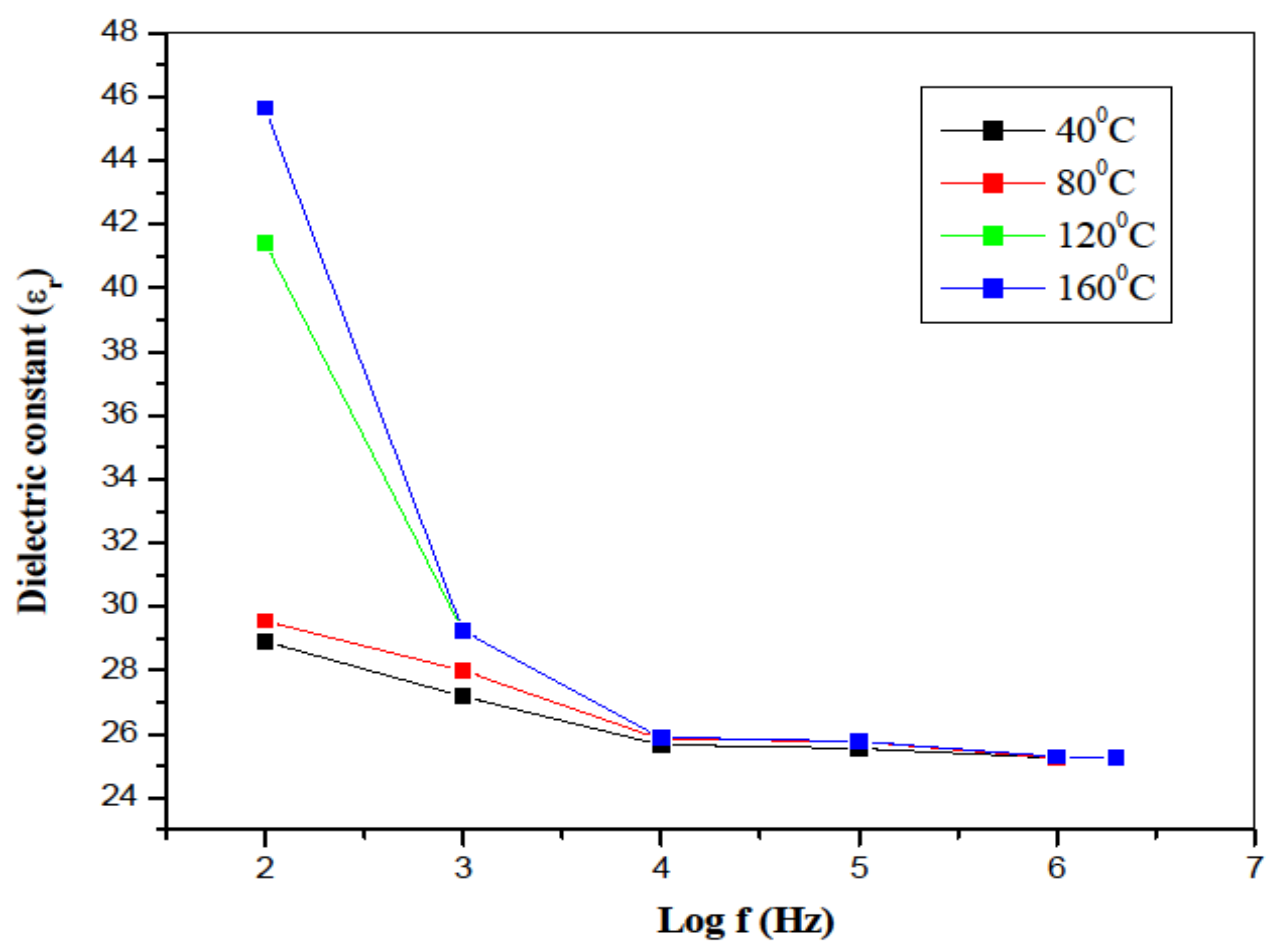

Fig.7.1 Plot between dielectric constant and $\log f$ of LTCS crystal

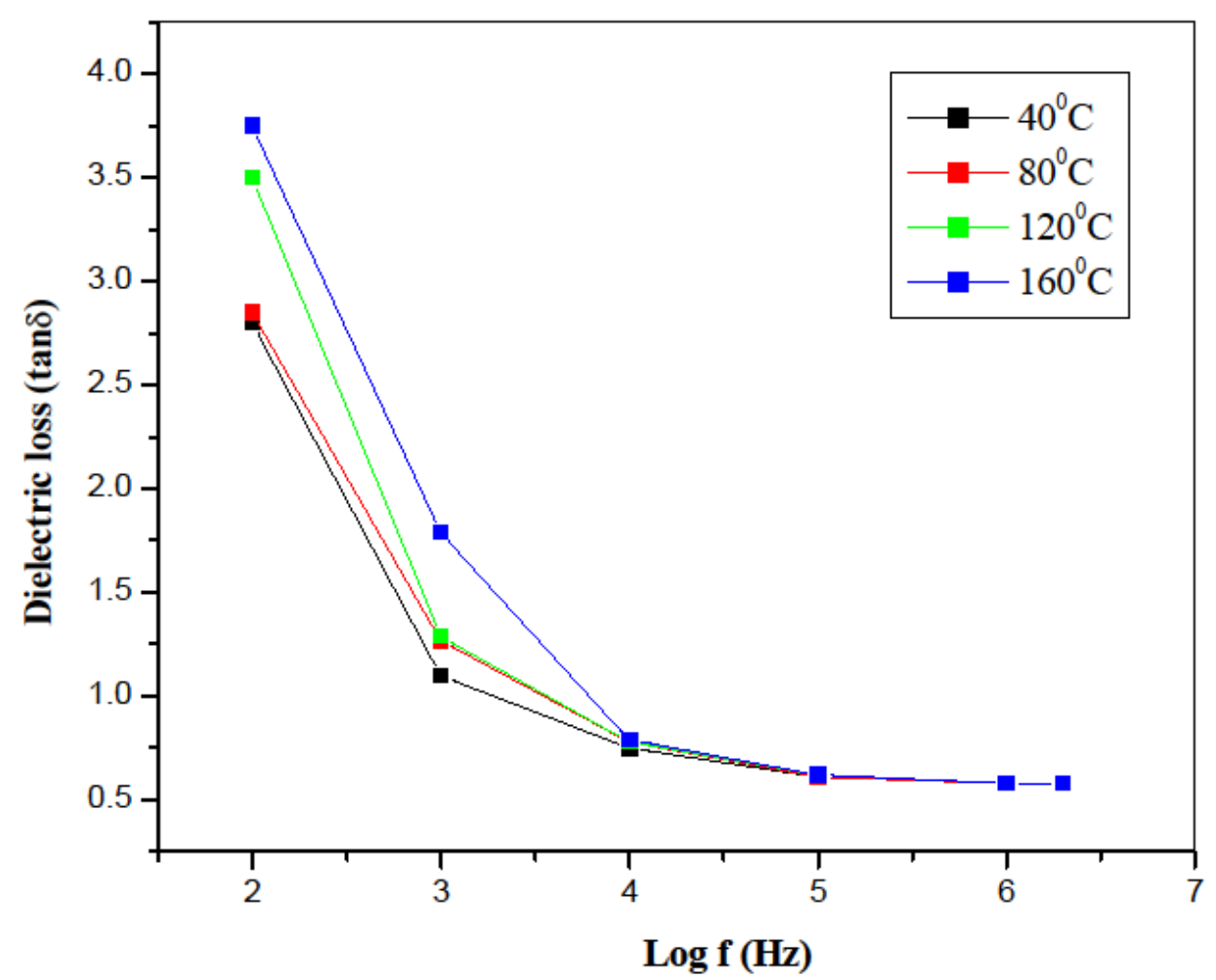

Fig.7.2 Plot between dielectric loss and $\log f$ of LTCS crystal 


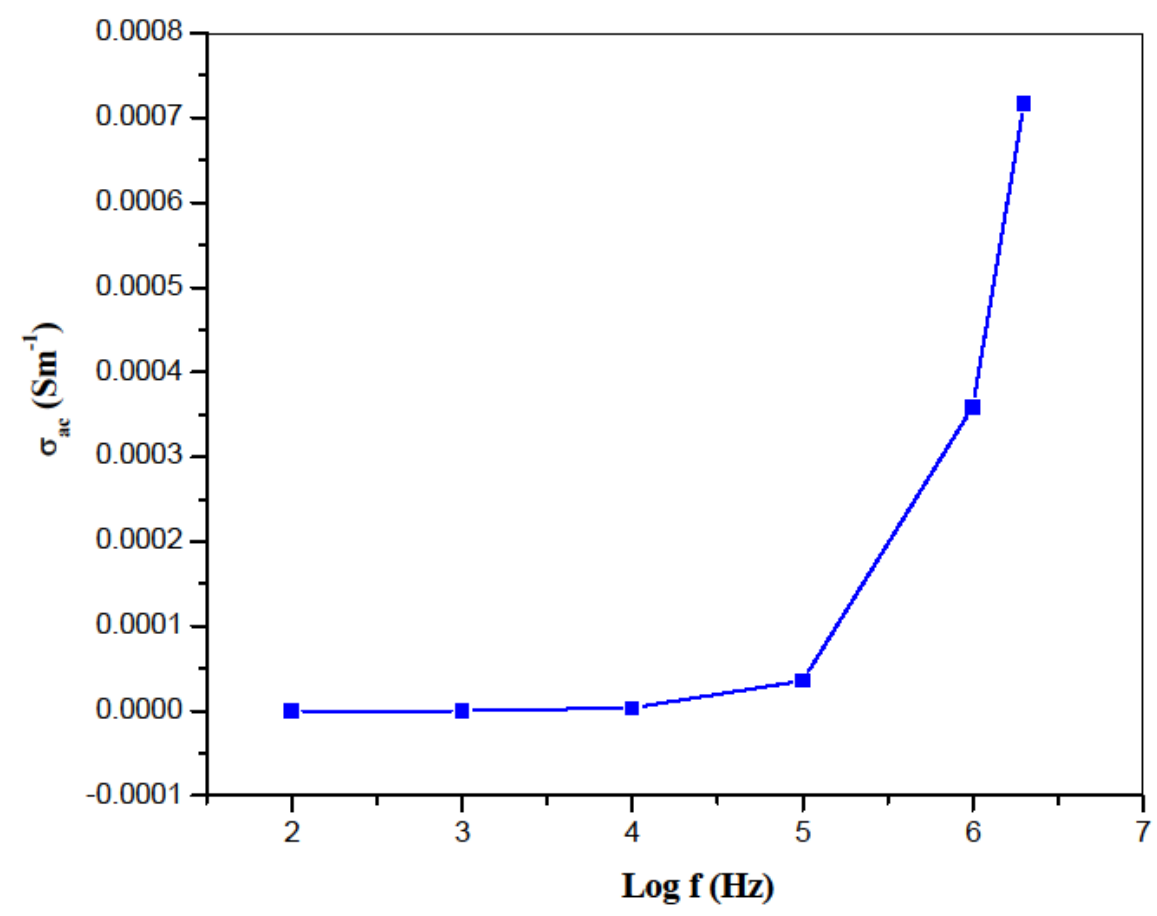

Fig.7.3 Plot between ac conductivity and $\log f$ of LTCS crystal

\subsection{Antimicrobial activity}

The microorganism used for study the antibacterial activity of the LTCS material is Pseudomonas aeruginosa and Staphylococcus aureus. Pseudomonas aeruginosa causes wide variety of infections in humans such as urinary tract infections, respiratory system infections, soft tissue infections etc. Staphylococcus aureus is the leading cause of skin and soft tissue infections [32, 33]. Fig.8.1 (a \& b) shows the inhibitory activity produced by two different pathogenic bacteria Pseudomonas aeruginosa and Staphylococcus aureus. After incubation, the zone of inhibition surrounding the disc was measured in millimeter and the obtained results are presented in Table 5. Among the two bacteria, Staphylococcus aureus showed high antibacterial activity $(31 \mathrm{~mm})$ than the control $(28 \mathrm{~mm})$ and also Pseudomonas aeruginosa have nearly equal activity of control. According to the results of this study, LTCS crystal has substantial antibacterial activity on Staphylococcus aureus than Pseudomonas aeruginosa. However, in this present study confirms the grown material is used to treat various bacterial infections produced by the given microorganism [34-36].

To access the antifungal activity of the grown sample using Candida albicans and Aspergillus flavus as test organisms. Some health problems caused by Aspergillus flavus include allergic reactions, lung infections, and infections in other organs. Candida albicans is not problematic at normal levels, when it grow 
uncontrollably the healthy bacteria levels are minimized this causes fungal infections in humans [37]. Antifungal susceptibility activity of LTCS crystal is shown in Fig.8.2 (a \& b) and the obtained results are presented in Table 5 and this study confirms the grown material makes high resistance to the most prevalent opportunistic fungal pathogens Aspergillus flavus than Candida albicans. In the context of above concern, the grown material is used to treat wide verity of fungal infection.

Table 5 Growth inhibition zones of LTCS crystal

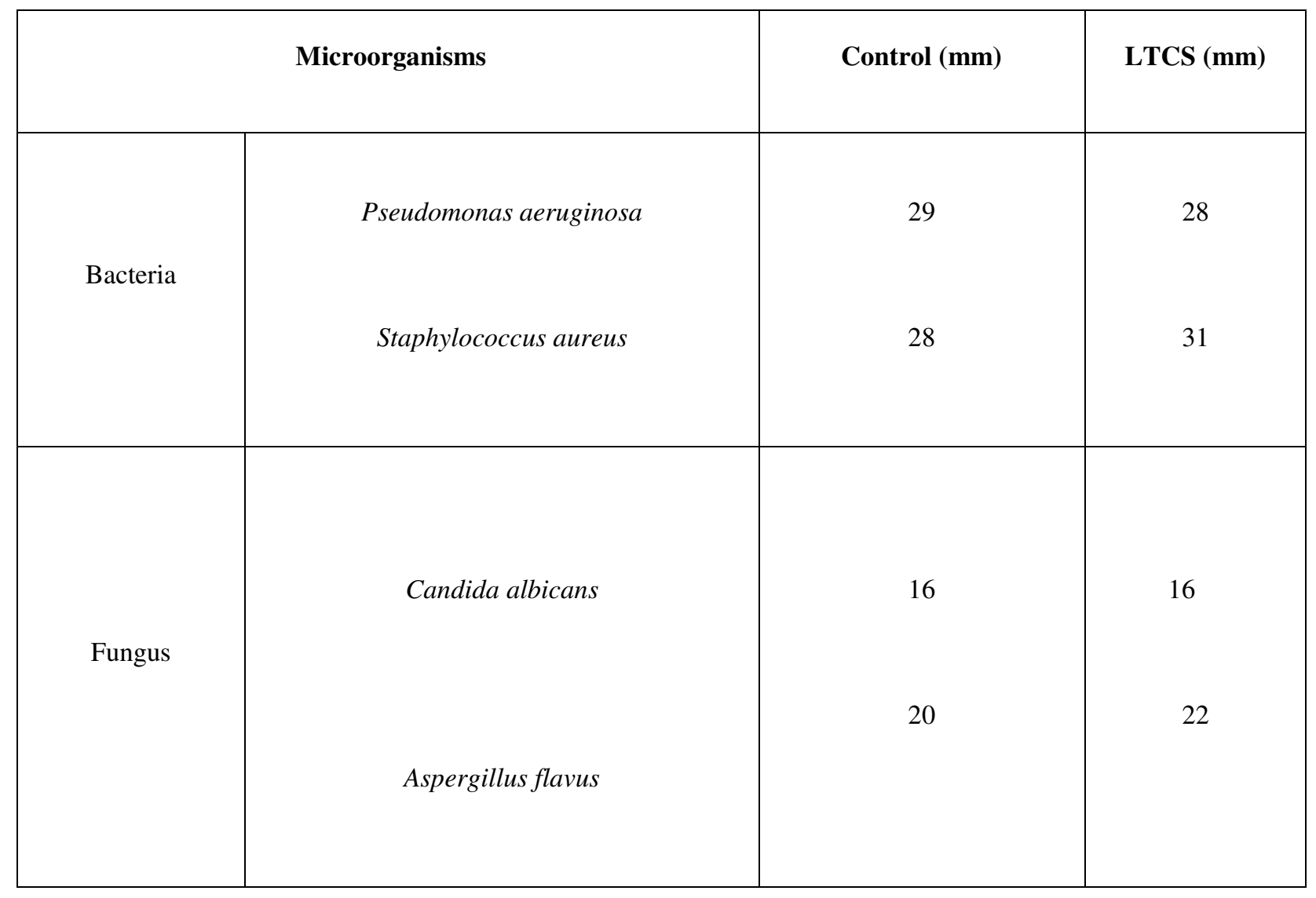



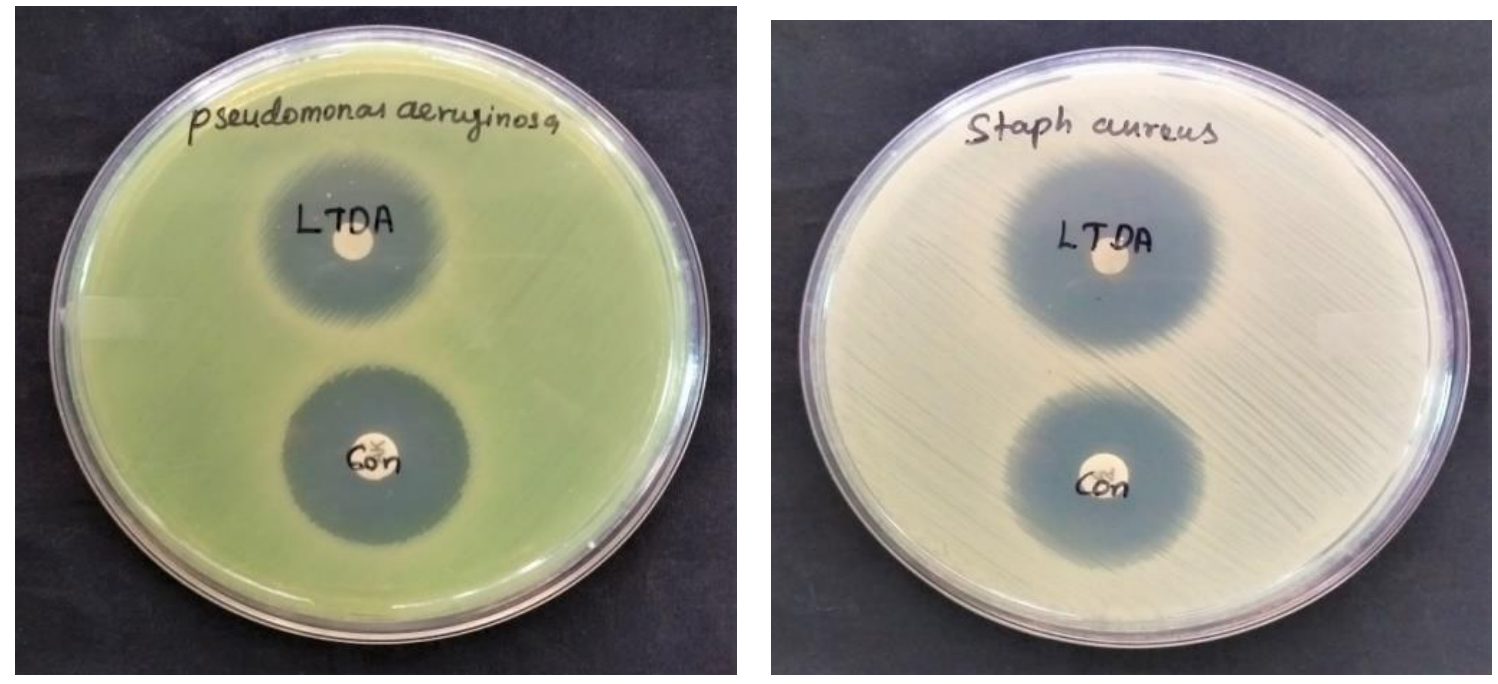

Fig.8.1 Antibacterial activity of LTCS crystal for two bacterial pathogens (a) ZOI of Pseudomonas aeruginosa (b) ZOI of Staphylococcus aureus
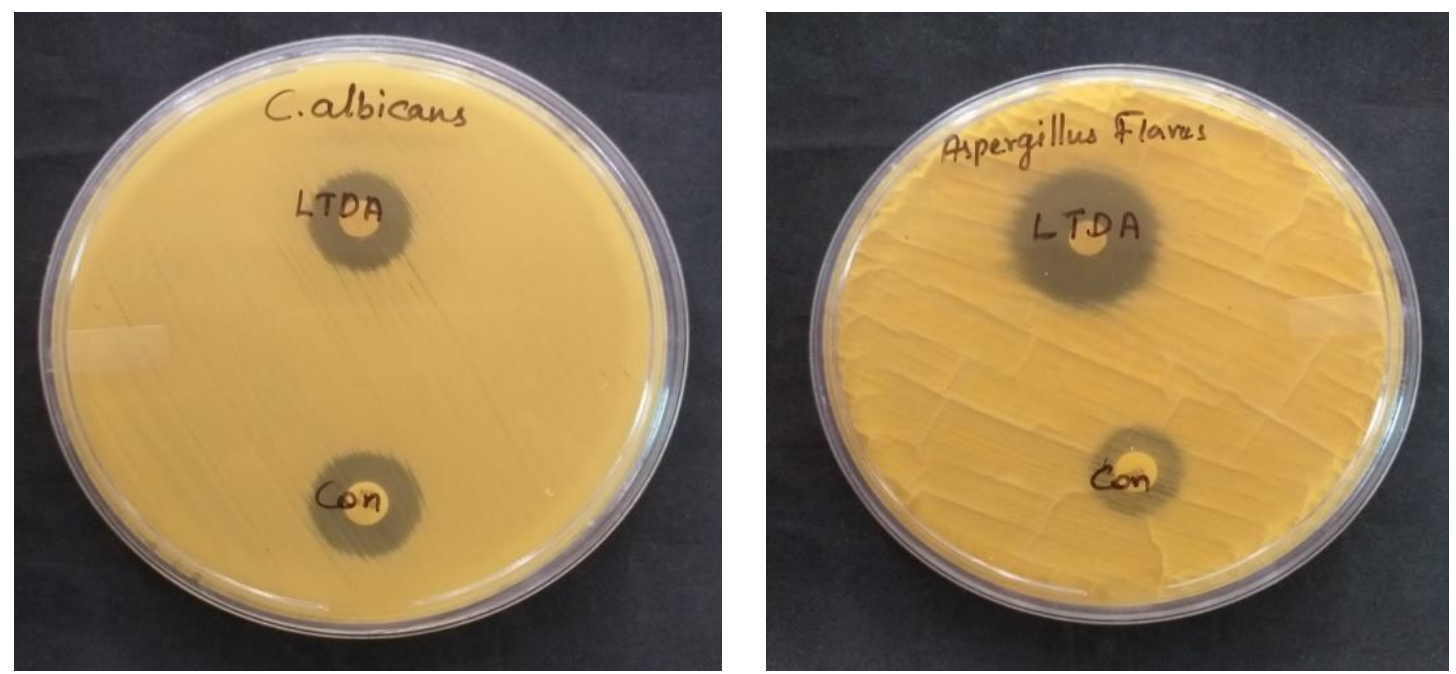

Fig.8.2 Antifungal activity of LTCS crystal for two fungal pathogens (a) Candida albicans (b) Aspergillus flavus

\section{CONCLUSIONS}

By using one of the oldest and most widely used slow evaporation crystal growth technique LTCS materials were grown. Diffraction studies (PXRD and SXRD) revealed the degree of structural order (crystallinity), cell parameters $(a=5.35, b=7.93, c=13.71)$, structure (orthorhombic), and space group (non- 
centrosymmetric) of the LTCS grown material. Functional groups were affirmed by FTIR analysis. Optical analysis unambiguously affirmed LTCS crystal possess greater optical transparency and $E g=5.6 \mathrm{eV}$, this confirms the suitability of the prepared crystals for NLO applications. With the help of Vickers's microhardness measurement the mechanical properties were confirmed and also it confirms that LTCS belongs to the hard material category. For LTCS crystal's SHG measurement unambiguously identifies $\mathrm{Co}^{+}$ion raises the SHG efficiency of 1.25 times higher than that of standard KDP crystal. LTCS's conducting properties were affirmed by electrical studies. The grown material has resistance about some bacteria and fungi which was confirmed by disc diffusion method.

\section{Acknowledgement}

The writers wish to express their gratitude to SAIF IIT, Chennai, Archbishop Casimir Instrumentation Center (ACIC), Tiruchirappalli, Ayya Nadar Janaki ammal College, Sivakasi, for the facilities given for different analyses.

\section{References}

[1] N. Bhuvaneswari, S. Nalini Jayanti, Effect of 1-threonine on optical and electrical properties of TTZS crystal. Mater.Today.5,3378-3389 (2018). https://doi.org/10.1016/j.matpr.2017.11.582

[2] Xiaoting Wang, Ruiying Li, Aogang Liu, Caipeng Yue, Shimin Wang, Jiajia Cheng, Jinpeng Li, Zhongyi Liu, Syntheses, crystal structures, antibacterial activities of $\mathrm{Cu}$ (II) and $\mathrm{Ni}(\mathrm{II})$ complexes based on terpyridine polycarboxylic acid ligand. J. Mol. Struct. 1184, 503-511 (2019). https://doi.org/10.1016/j.molstruc.2019.02.072.

[3] A.A. Al-Sagan, S. Khalil, M.P. Smith, The Benefit of L-Threonine Supplementation on Growth Performance, Carcass Characteristics, Intestinal Morphology and Litter Quality of Broilers. Rev. Bras. Cienc. Avic. 20, 753-758 (2018). http://dx.doi.org/10.1590/1806-9061-2018-0764.

[4] S.V.Ashvin Santhia, B.Aneeba, S.Vinu, R.Sheela Christy, Amal M.Al-Mohaimeed, Dunia A.Al Farraj, Studies on physicochemical and antibacterial deeds of amino acid based L-Threoninum sodium bromide. Saudi J. Biol. Sci. 27, 2987-2992 (2020). https://doi.org/10.1016/j.sjbs.2020.09.020.

[5] L. M. Cavaco, H. Hasman, M. Stegger, P. S. Andersen, R. Skov, A. C. Fluit, T. Ito, F. M. Aarestrup, Cloning and occurrence of czrC, a gene conferring cadmium and zinc resistance in methicillin-resistant 
Staphylococcus aureus CC398 isolates. Antimicrob. Agents Chemother. 54, 3605-8 (2010). https://doi.org/10.1128/AAC.00058-10.

[6] D. A. Abila Darling., S. E Joema, Antibacterial activity, optical, mechanical, thermal, and dielectric properties of L-phenylalanine fumaric acid single crystals for biomedical, optoelectronic, and photonic applications. J. Mater. Sci.: Mater. 31, 22427-22441 (2020). https://doi:10.1007/s10854-020-04744-2

[7] M.Rajkumar, M.Saravanabhavan, A.Chandramohan, Synthesis, structural, thermal, mechanical, second harmonic generation efficiency and laser damage threshold studies of 4-dimethylaminopyridinium-3,5dicarboxybenzoate trihydrate single crystal. Opt. Mater.72, 247-256 (2017). https://doi.org/10.1016/j.optmat.2017.06.011

[8] A.Priyadharshini, S.Kalainathan, Synthesis, crystal growth and characterization of third order NLO active single crystal: 2-(4-ethylbenzylidene) malononitrile (EBM). J. Phys. Chem. Solids.123, 59-69 (2018). https://doi.org/10.1016/j.jpcs.2018.07.011

[9] S. Masilamani, A. Mohamed Musthafa, P. Krishnamurthi, Synthesis, growth and characterisation of a semiorganic nonlinear optical material: 1-threonine cadmium chloride single crystals. Arab. J. Chem. 10, 39623966 (2017). https://doi.org/10.1016/j.arabjc.2014.06.003

[10] M. Abila Jeba Queen, K.C. Bright, S. Mary Delphine , P. Aji Udhaya, Spectroscopic investigation of supramolecular organometallic compound L-threonine cadmium acetate monohydrate. Spectrochimica Acta Part A: Molecular and Biomolecular Spectroscopy. 228, 117802 (2020). https://doi.org/10.1016/j.saa.2019.117802

[11] Roniel L.Araújo, Manoel S.Vasconcelos, Carlos A.Barboza, José X.Lima Neto, Eudenilson L.Albuquerque, Umberto L.Fulco, DFT calculations of the structural, electronic, optical and vibrational properties of anhydrous orthorhombic L-threonine crystalsComput. Theor. Chem. 1170, 112621 (2019). https://doi.org/10.1016/j.comptc.2019.112621

[12] J.H. Joshi, S. Kalainathan, D.K. Kanchan, M.J. Joshi, K.D. Parikh, Effect of L-threonine on growth and properties of ammonium dihydrogen phosphate crystal. Arab. J. Chem. 13, 1532-1550 (2020). https://www.xmol.com/paperRedirect/492742 
[13] J.Chandrasekaran, P.Ilayabarathi, P.Maadeswaran, Crystal growth and characterization of L-valine cadmium acetate a semiorganic NLO crystals. Opt. Commun. 285, 3872-3876 (2012). http://dx.doi.org/10.13005/ojc/290416

[14] J. Tauc, Amorphous and liquid semiconductors, J. Tauc Ed.Plenum, New York, 1974.

[15] P.Karuppasamy, T.Kamalesh, K.Anitha, MuthuSenthil Pandian, P.Ramasamy, SunilVerma, Design and growth of novel organic molecular Quinoline 4-nitrophenol (QNP) single crystals: For Nonlinear optical (NLO) applications. J. Mol. Struct. 1210, 128036 (2020). https://doi.org/10.1016/j.molstruc.2020.128036

[16] B. Aneeba, S.V. Ashvin Santhia, S. Vinu, R. Sheela Christy, Dunia A. Al Farraj, Noorah A. Alkubaisi, Influence of most reactive inorganic cation in the optical and biological activities of L-Lysine monohydrochloride crystal. Saudi J. Biol. Sci. 27, 2961-2967 (2020). https://doi.org/10.1016/j.sjbs.2020.07.018

[17] T.UmaDevi, N.Lawrence, R.Ramesh Babu, K.Ramamurthi, Growth and characterization L-prolinium picrate single crystal:a promising NLO crystal, J. Cryst.Growth. 310, 116-123 (2008). https://doi.org/10.1016/j.jcrysgro.2007.10.011

[18] Suresh, Sagadevan, Synthesis, growth and characterization of L-threonine zinc acetate (LTZA) NLO single crystal. Optik (Stuttg.). 125, 4547-4551(2014). https://doi.org/10.1016/j.ijleo.2014.02.008

[19] S.Masilamani, A.Mohamed Musthafa ,P.Krishnamurthi, Synthesis, growth and characterisation of a semiorganic nonlinear optical material: L-threonine cadmium chloride single crystals. Arab. J. Chem. 10, S3962S3966 (2017). https://doi.org/10.1016/j.arabjc.2014.06.003

[20] S.A.Martin Britto Das, G.Bhagavannarayana, S.Natarajan, Growth and characterization of new potential NLO material from the amini acid family L-prolinium picrate. J. Cryst.Growth. 310 ,3535-3559 (2008). https://doi.org/10.1002/crat.200610850

[21] A. P. Arthi, M. Sumithra Devi, K. Thamizharasan, Structural, Microhardness, Photoconductivity, and Dielectric Properties of Tris(thiourea) Cadmium Sulphate Single Crystals. Solid State Phys. 2014, 5 (2014). https://doi.org/10.1155/2014/153272

[22] S. E. Allen Moses,S Tamilselven, S. M. Ravi Kumar, G.Vinitha,Tejaswi Ashok Hegde,M. Vimalan, S. Varalakshmi,S. Sivaraj, Synthesis,Growth and physicochemical properties of new organic nonlinear optical 
crystal L-threonium tartarate(LTT) for frequency conversion. Materials Science for Energy Technologies. 2, 565-574 (2019). https://doi.org/10.1016/j.mset.2019.05.003

[23] R.Subhashini, S.Arjunan, B.Gunasekaran, Synthesis of a metal coordinated amino acid based nonlinear single crystal, Bis(L-threonine)zinc(II) using the solution growth technique and its physicochemical properties. J. Phys. Chem. Solids. 135, 109077 (2019). https://doi.org/10.1016/j.jpcs.2019.109077

[24] S. Chennakrishnan, S. M. Ravi Kumar, C. Shanthi, R. Srineevasan, T. Kubendiran, Dsivavishnu, M. Packiya Raj, Synthesis of the semi-organic nonlinear optical crystal L-glutamic acid chloride and investigation of its growth and physiochemical properties. J. Taibah Univ. Sci. 11, 955-965 (2017). https://doi.org/10.1016/j.jtusci.2017.01.001

[25] S.K.Kurtz, T.Perry, A powder technique for the evaluation of nonlinear optical material, J.Appl.Phys. 39, 3798-3813 (1968). https://doi.org/10.1063/1.1656857

[26] N.Bhuvaneswari, S. Nalini Jayanti, Effect of 1-threonine on optical and electrical properties of TTZS crystal. Mater. Today. 5, 3378-3389 (2018). https://doi.org/10.1016/j.matpr.2017.11.582

[27] ImranKhan, MohdAnis, UmarBhati, Influence of L-lysine on optical and dielectric traits of cadmium thiourea acetate complex crystal. Optik.170, $43-47$ (2018). https://doi.org/10.1016/j.ijleo.2018.05.076

[28] G.Ramesh Kumar, S.Gokul Raj, Amit Saxena, A.K. Karnal, R. Mohan, Thenneti Raghavalu, Deuteration effects on structural ,thermal, linear and nonlinear properties of L-threonine single crystal. Mater. Chem. Phys. 108, 359-363 (2008). https://doi.org/10.1016/j.matchemphys.2007.10.015

[29] Redrothu Hanumantharao, S.Kalainathan ,Growth, spectroscopy, dielectric and nonlinear optical studies of novel organic NLO crystal: L-Threonine formate. Spectrochimica Acta Part A: Molecular and Biomolecular Spectroscopy. 94, 78-83 (2012). https://doi.org/10.1016/j.saa.2012.03.062

[30] G.R.Dillip, G.Bhagavannarayana, P.Raghavaiah, B.Deva Prasad Raju, Effect of magnesium chloride on growth, crystalline perfection, structural, optical, thermal and NLO behavior of $\gamma$-glycine crystals. Mater. Chem. Phys. 134, 371-376 (2012). https://doi.org/10.1016/j.matchemphys.2012.03.004 
[31] M. Packiya raj, S.M. Ravi Kumar, R. Srineevasan, R. Ravisankar, Synthesis, growth, and structural, optical, mechanical, electrical properties of a new inorganic nonlinear optical crystal: Sodium manganese tetrachloride (SMTC). J. Taibah Univ. Sci. 11, 76-84 (2017). https://doi.org/10.1016/j.jtusci.2015.08.006.

[32] V.Revathi, K.Karthik, Physico-chemical properties and antibacterial activity of Hexakis (Thiocarbamide) Nickel(II) nitrate single crystal. Chemical Data Collections. 21, 100229 (2019). https://doi.org/10.1016/j.cdc.2019.100229

[33] V. Revathi, K. Karthik, Hakimeh Mahdizadeh, Antibacterial activity and physico-chemical properties of metal-organic single crystal: Zinc (Tris) thiourea chloride. Chemical Data ollections. 24, 100279 (2019). https://doi.org/10.1016/j.cdc.2019.100279

[34] B. Deepa , P. Philominathan, Enhanced NLO and antibacterial properties of nicotinic acid-doped KDP crystals: synthesis, growth and characterization. Mater. Res. Innov.21, 86-90 (2017). https://doi.org/10.1080/14328917.2016.1191794

[35] S Priya, K. Balakrishnan, P. Surendran, A. Lakshmanan, P. Geetha, P. Rameshkumar, , Hegde, Tejaswi, G. Vinitha, Raj, Antony, Investigations on Structural, Mechanical, Optical, Electrical, Third-Order Nonlinear Optical and Antibacterial Activity of 4-Aminopyridine Monophthalate Single Crystal. J. Electron. Mater. 50, 1-12(2020). https://doi.org/ 10.1007/s11664-020-08497-w

[36] Fatma Mohamed A. Abid, JoazaizulfazliJamalis, Subhash Chander, Roswanira Abd Wahab, Deepak P. Bhagwat, Murugesan Sankaranarayanan, Synthesis, characterization, in silico and antifungal studies of thiazolidine analogues.21, 100219 (2019). https://doi.org/10.1016/j.cdc.2019.100219

[37] B. Aneeba, S.V. Ashvin Santhia, R. Sheela Christy, Fahad A. Al-Misned, Hamed A. El-Serehy, S. Vinu,

Polychromatic luminescence and improved antifungal performance of succinic acid in the lattice of L-Lysine monohydrochloride. Saudi J. Biol. Sci. 28, 395-399 (2021). https://doi.org/10.1016/j.sjbs.2020.10.021. 
Figures

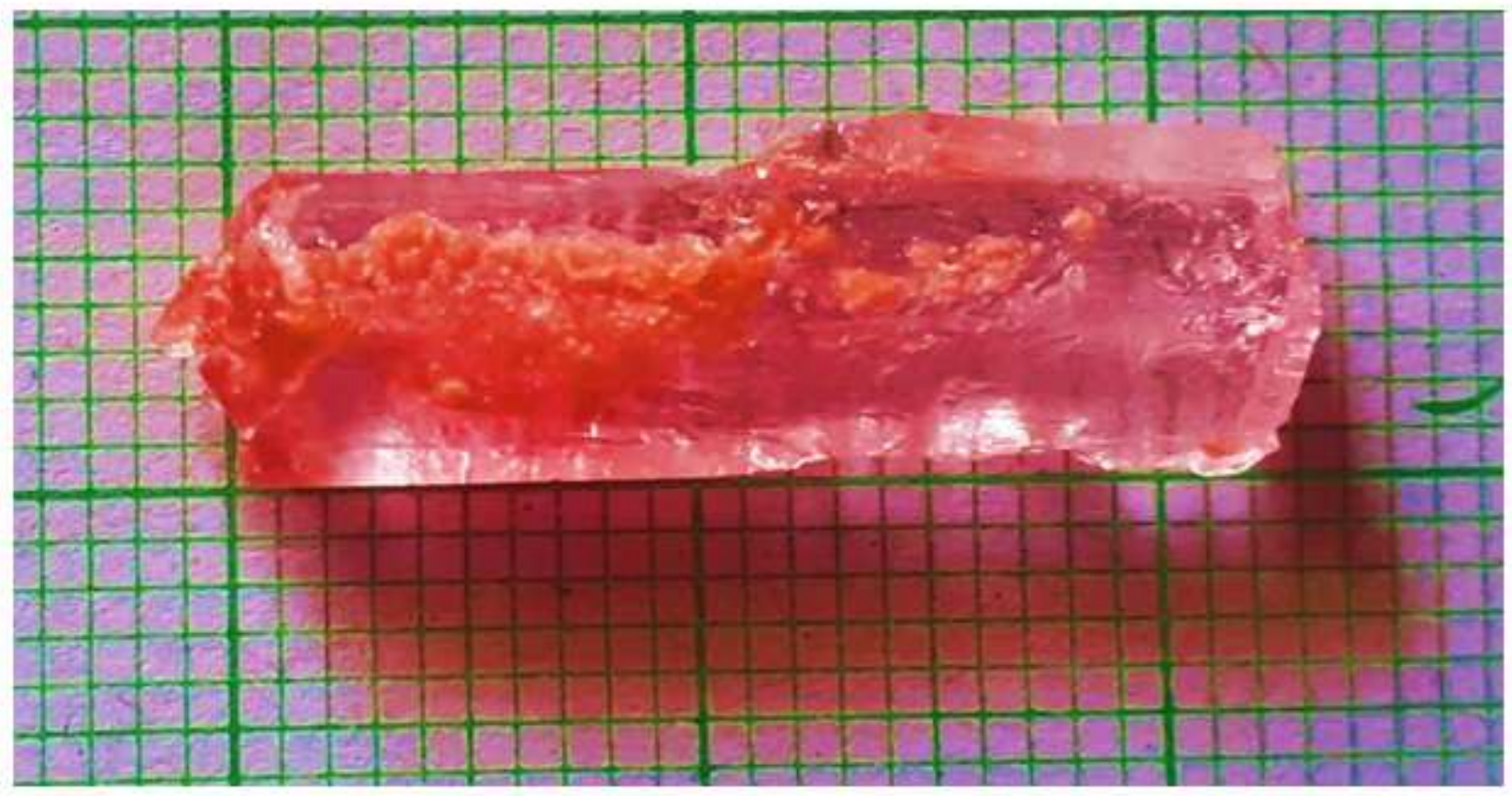

Figure 1

Photograph of LTCS single crystal

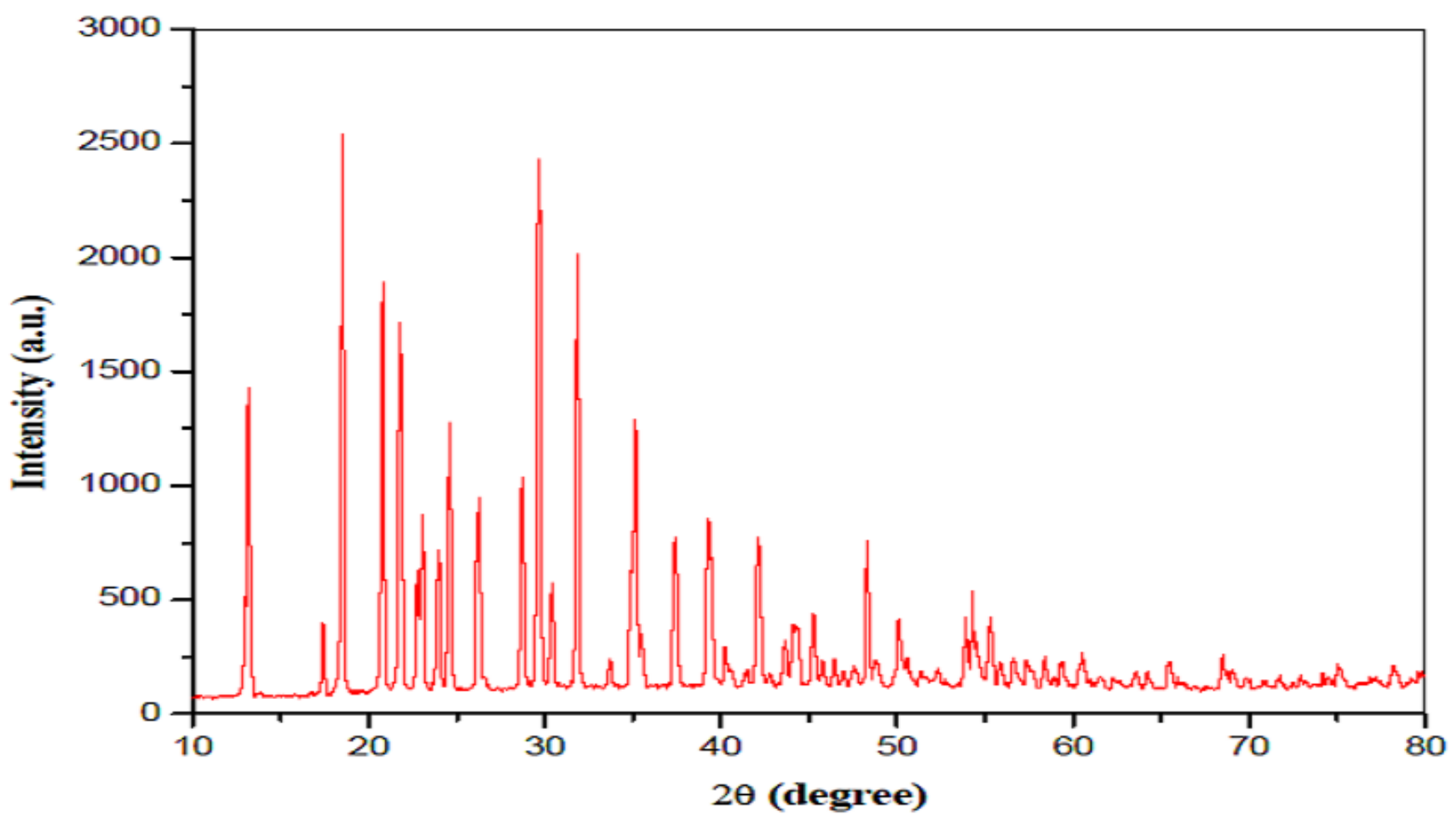

Figure 2 
Powder XRD pattern of LTCS crystal

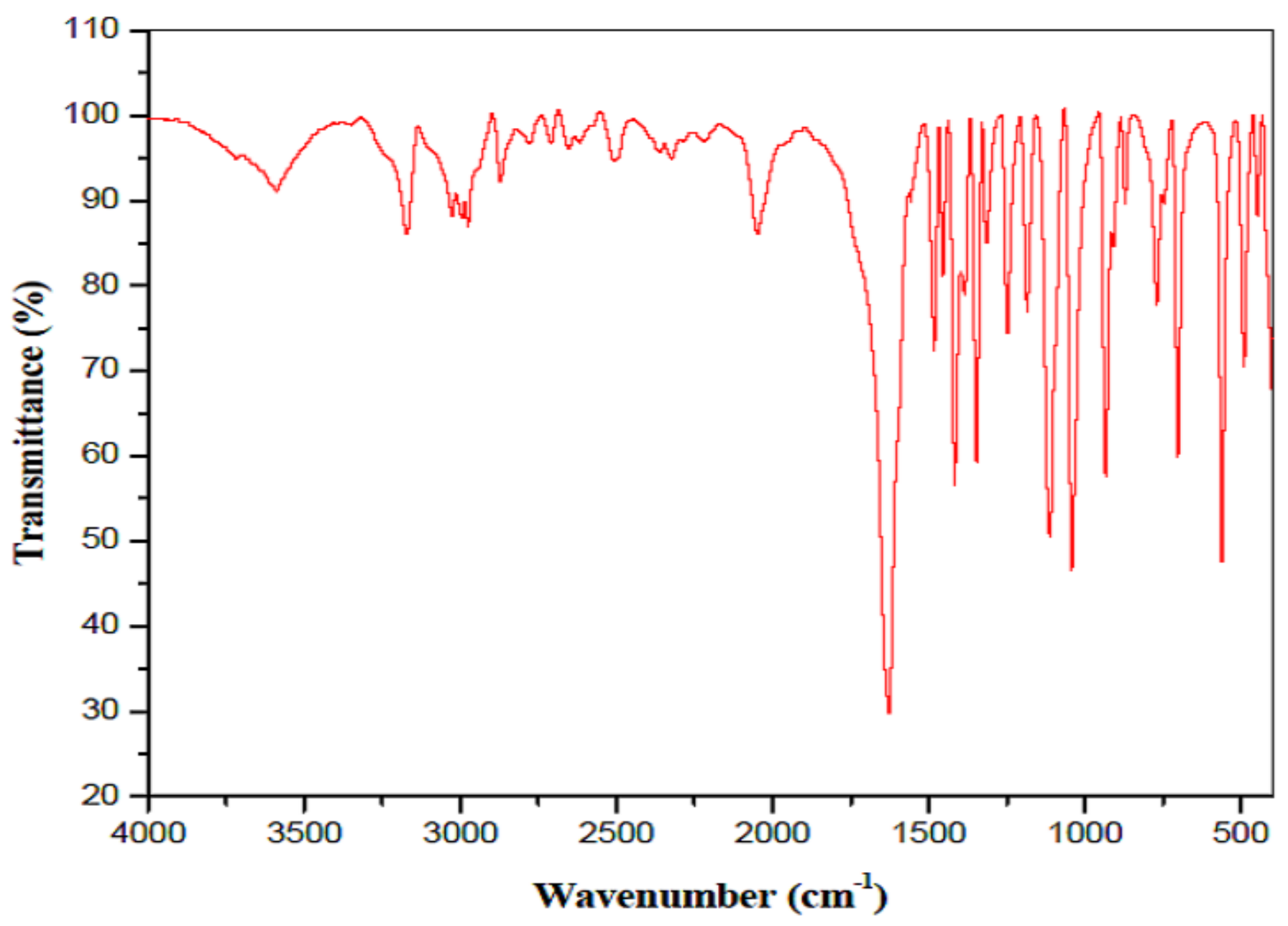

Figure 3

FTIR spectra of LTCS crystal 


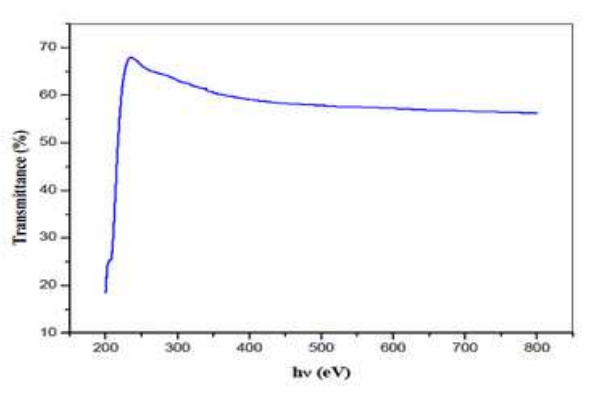

4.1

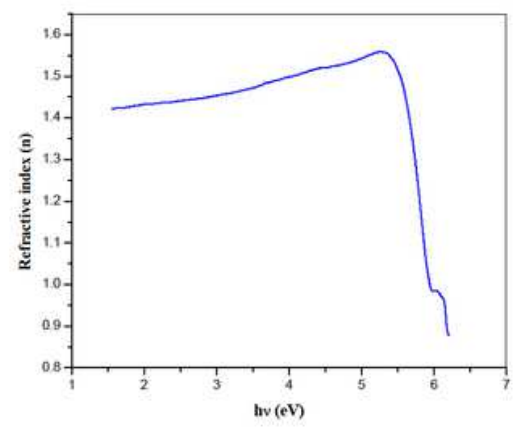

4.4

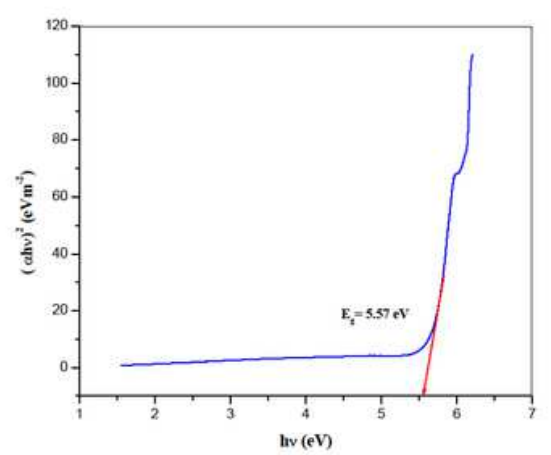

4.2

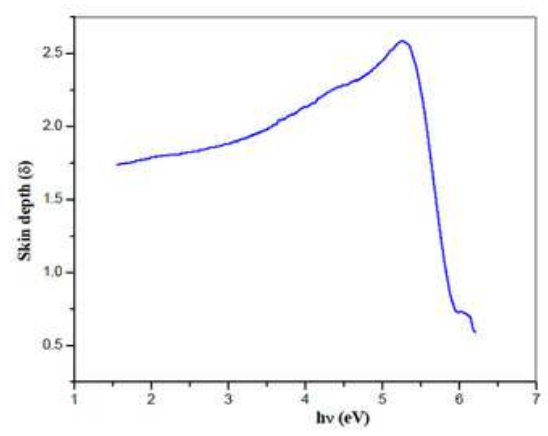

4.5

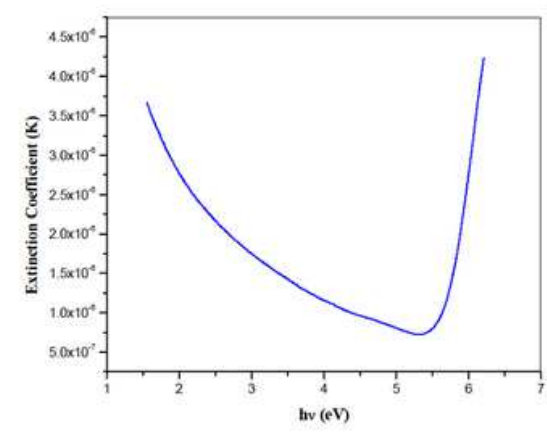

4.3

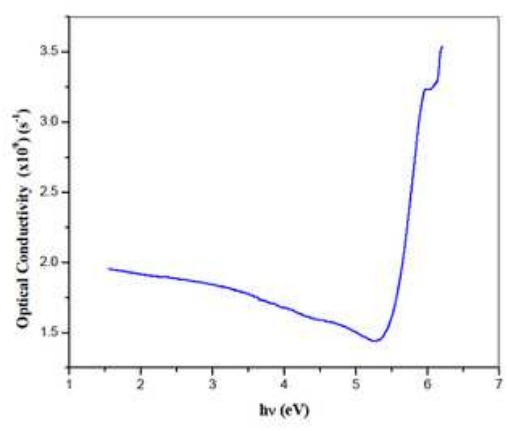

4.6

\section{Figure 4}

4.1 Transmission spectra of LTCS crystal 4.2 Plot of (ahv) 2 versus Photon energy (hv) of LTCS crystal 4.3 Photon energy versus Extinction Coefficient of LTCS crystal 4.4 Photon energy versus refractive indices of LTCS crystal 4.5 Photon energy versus Skin depth of LTCS crystal 4.6 Photon energy versus optical conductivity of LTCS crystal 


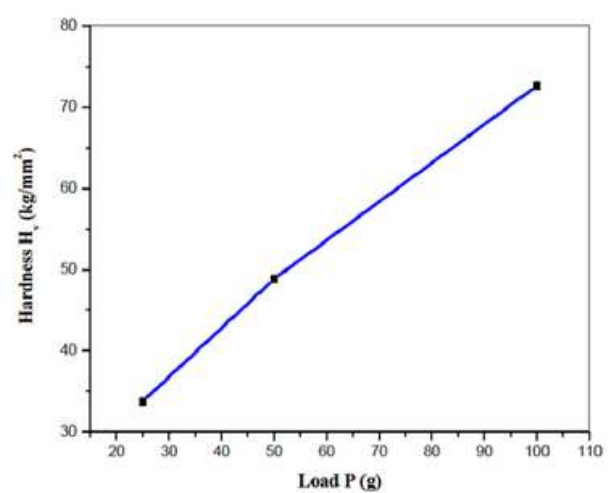

5.1

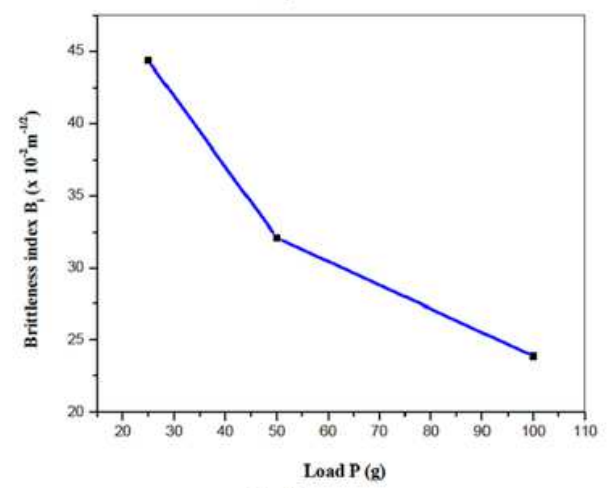

5.4

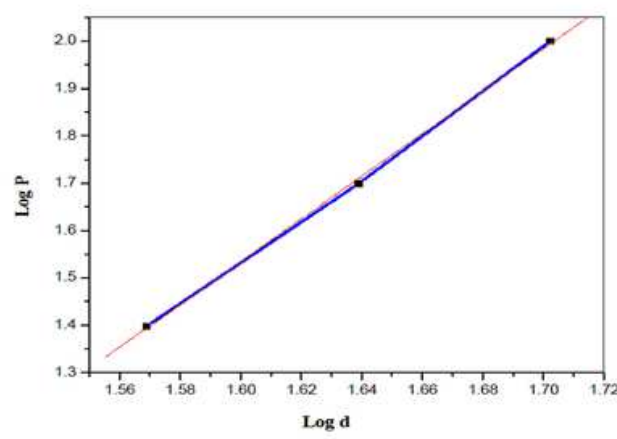

5.2

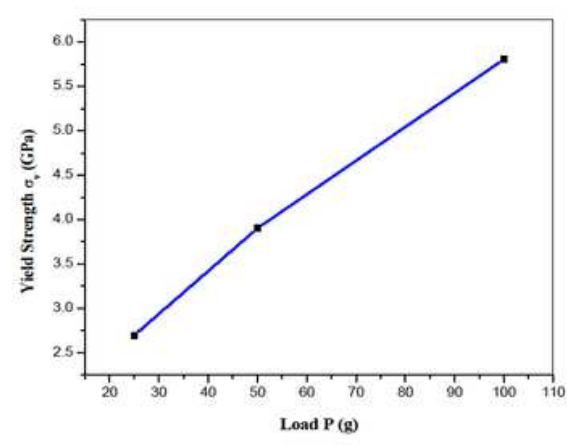

5.5

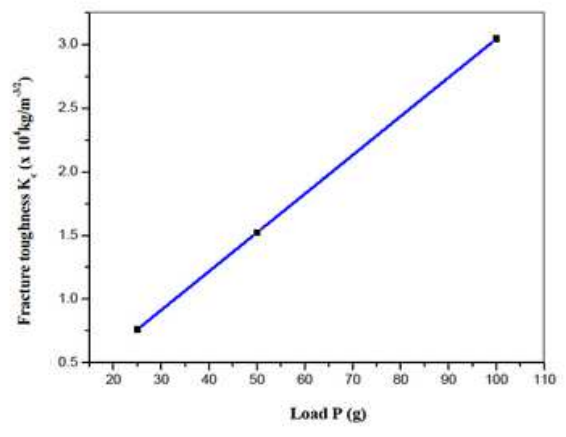

5.3

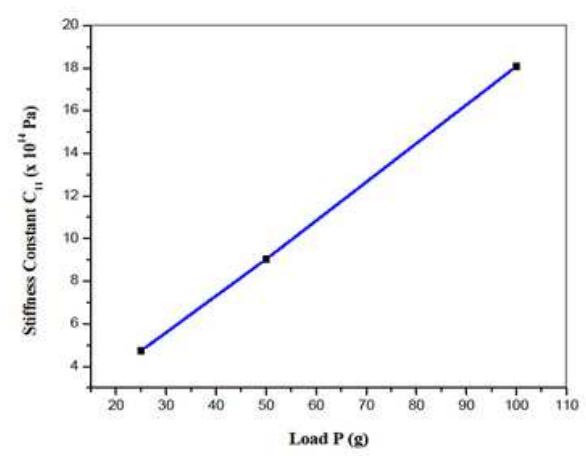

5.6

\section{Figure 5}

5.1 Hardness versus load P of LTCS crystal 5.2 Log P versus Log d of LTCS crystal 5.3 Fracture toughness versus load P of LTCS crystal 5.4 Brittleness index versus load P of LTCS crystal 5.5 Yield Strength versus load P of LTCS crystal 5.6 Stiffness constant versus load P of LTCS crystal

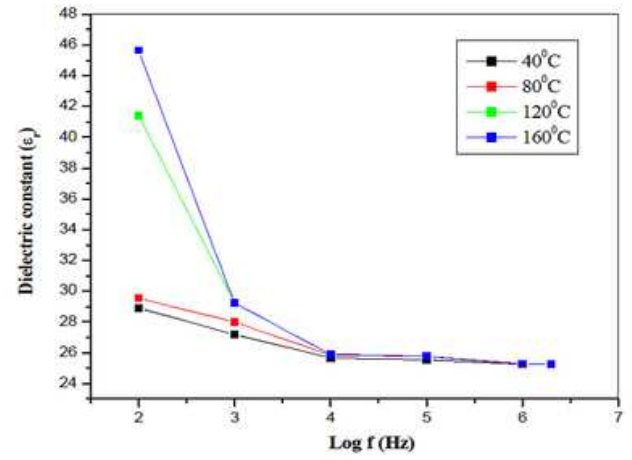

7.1

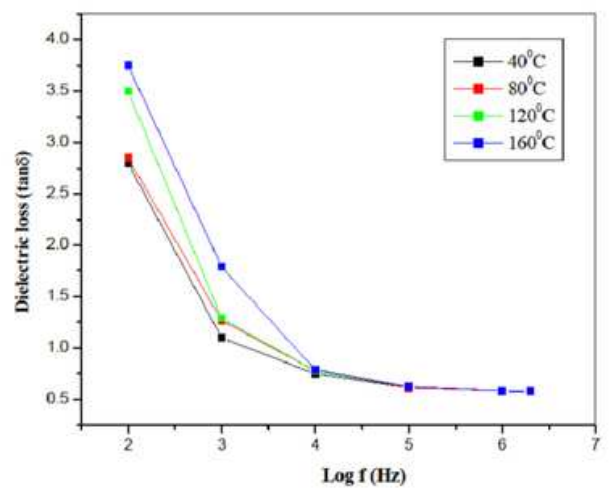

7.2

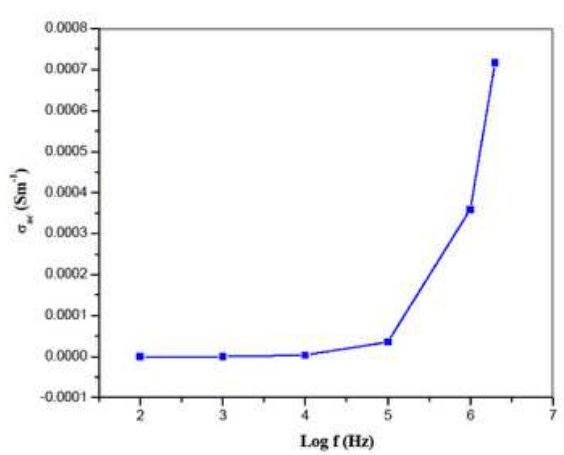

7.3

\section{Figure 6}

7.1 Plot between dielectric constant and log $f$ of LTCS crystal 7.2 Plot between dielectric loss and log $f$ of LTCS crystal 7.3 Plot between ac conductivity and log f of LTCS crystal 

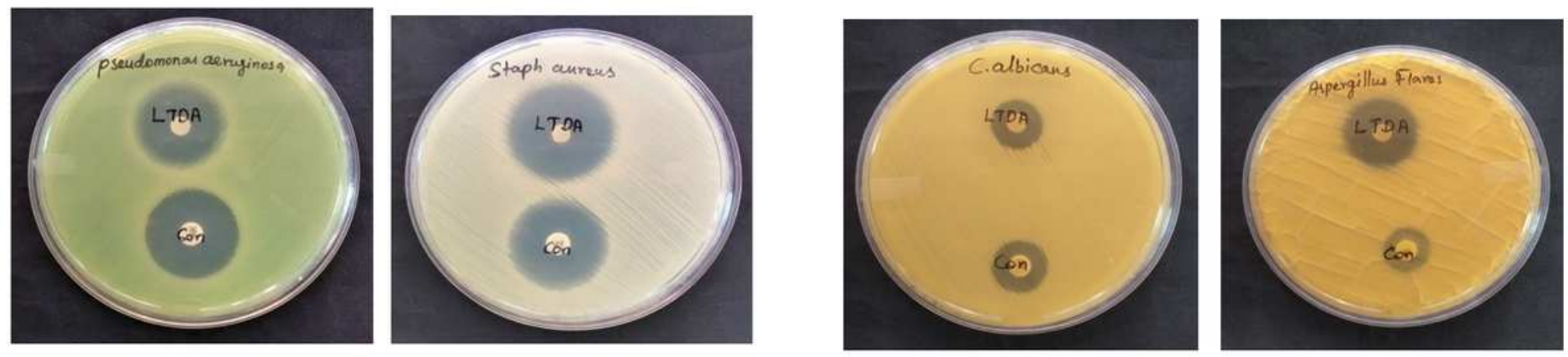

8.1

\section{2}

Figure 7

8.1 Antibacterial activity of LTCS crystal for two bacterial pathogens (a) ZOI of Pseudomonas aeruginosa (b) ZOI of Staphylococcus aureus 8.2 Antifungal activity of LTCS crystal for two fungal pathogens (a) Candida albicans (b) Aspergillus 